Cochrane Database of Systematic Reviews

\title{
Tonsillectomy for periodic fever, aphthous stomatitis, pharyngitis and cervical adenitis syndrome (PFAPA) (Review)
}

\author{
Burton MJ, Pollard AJ, Ramsden JD, Chong LY, Venekamp RP
}

Burton MJ, Pollard AJ, Ramsden JD, Chong LY, Venekamp RP.

Tonsillectomy for periodic fever, aphthous stomatitis, pharyngitis and cervical adenitis syndrome (PFAPA).

Cochrane Database of Systematic Reviews 2019, Issue 12. Art. No.: CD008669.

DOI: 10.1002/14651858.CD008669.pub3.

www.cochranelibrary.com 
TABLE OF CONTENTS

HEADER 1

ABSTRACT

PLAIN LANGUAGE SUMMARY

SUMMARY OF FINDINGS

BACKGROUND

OBJECTIVES

METHODS

RESULTS

Figure 1.

Figure 2.

Figure 3.

DISCUSSION

AUTHORS' CONCLUSIONS

ACKNOWLEDGEMENTS

REFERENCES

CHARACTERISTICS OF STUDIES

DATA AND ANALYSES

Analysis 1.1. Comparison 1 Surgery (tonsillectomy +/- adenoidectomy) versus control, Outcome 1 Proportion of patients whose symptoms have completely resolved.

Analysis 1.2. Comparison 1 Surgery (tonsillectomy +/- adenoidectomy) versus control, Outcome 2 Number of episodes of fever and associated symptoms (per person-month).

Analysis 1.3. Comparison 1 Surgery (tonsillectomy +/-adenoidectomy) versus control, Outcome 3 Use of corticosteroids. APPENDICES

WHAT'S NEW

HISTORY

CONTRIBUTIONS OF AUTHORS

DECLARATIONS OF INTEREST

SOURCES OF SUPPORT

DIFFERENCES BETWEEN PROTOCOL AND REVIEW

INDEX TERMS 
[Intervention Review]

\section{Tonsillectomy for periodic fever, aphthous stomatitis, pharyngitis and cervical adenitis syndrome (PFAPA)}

Martin J Burton ${ }^{1}$, Andrew J Pollard², James D Ramsden ${ }^{3}$, Lee-Yee Chong ${ }^{4}$, Roderick P Venekamp 5

1Cochrane UK, Oxford, UK. 2Department of Paediatrics, University of Oxford, Children's Hospital, Oxford, UK. 3Department of Otolaryngology - Head and Neck Surgery, Oxford Radcliffe Hospitals NHS Trust, Oxford, UK. 4UK Cochrane Centre, Oxford, UK. 5 Julius Center for Health Sciences and Primary Care \& Department of Otorhinolaryngology, University Medical Center Utrecht, Utrecht University, Utrecht, Netherlands

Contact address: Martin J Burton, Cochrane UK, Summertown Pavilion, 18 - 24 Middle Way, Oxford, OX2 7LG, UK. martin.burton@cochrane.nhs.uk.

Editorial group: Cochrane ENT Group

Publication status and date: New search for studies and content updated (no change to conclusions), published in Issue 12, 2019.

Citation: Burton MJ, Pollard AJ, Ramsden JD, Chong LY, Venekamp RP. Tonsillectomy for periodic fever, aphthous stomatitis, pharyngitis and cervical adenitis syndrome (PFAPA). Cochrane Database of Systematic Reviews 2019, Issue 12. Art. No.: CD008669. DOI: 10.1002/14651858.CD008669.pub3.

Copyright (c 2019 The Cochrane Collaboration. Published by John Wiley \& Sons, Ltd.

\section{A B S T R A C T}

\section{Background}

Periodic fever, aphthous stomatitis, pharyngitis and cervical adenitis (PFAPA) syndrome is a rare clinical syndrome of unknown cause usually identified in children. Tonsillectomy is considered a potential treatment option for this syndrome. This is an update of a Cochrane Review first published in 2010 and previously updated in 2014.

\section{Objectives}

To assess the effectiveness and safety of tonsillectomy (with or without adenoidectomy) compared with non-surgical treatment in the management of children with PFAPA.

\section{Search methods}

The Cochrane ENT Information Specialist searched the Cochrane ENT Trials Register; Central Register of Controlled Trials (CENTRAL 2019, Issue 4); PubMed; Ovid Embase; CINAHL; Web of Science; ClinicalTrials.gov; ICTRP and additional sources for published and unpublished trials. The date of the search was 15 October 2019.

\section{Selection criteria}

Randomised controlled trials comparing tonsillectomy (with or without adenoidectomy) with non-surgical treatment in children with PFAPA.

\section{Data collection and analysis}

We used the standard methodological procedures expected by Cochrane. The primary outcomes were the proportion of children whose symptoms have completely resolved and complications of surgery (haemorrhage and number of days of postoperative pain). Secondary outcomes were: number of episodes of fever and the associated symptoms; severity of episodes; use of corticosteroids; absence or time off school; quality of life. We used GRADE to assess the certainty of the evidence for each outcome.

\section{Main results}

Two trials were included with a total of 67 children randomised ( 65 analysed); we judged both to be at low risk of bias. 
One trial of 39 participants recruited children with PFAPA syndrome diagnosed according to rigid, standard criteria. The trial compared adenotonsillectomy to watchful waiting and followed up patients for 18 months. A smaller trial of 28 children applied less stringent criteria for diagnosing PFAPA and probably also included participants with alternative types of recurrent pharyngitis. This trial compared tonsillectomy alone to no treatment and followed up patients for six months.

Combining the trial results suggests that patients with PFAPA likely experience less fever and less severe episodes after surgery compared to those receiving no surgery. The risk ratio (RR) for immediate resolution of symptoms after surgery that persisted until the end of followup was 4.38 (95\% confidence interval ( $\mathrm{Cl}) 0.64$ to 30.11 ); number needed to treat to benefit (NNTB) $=2$, calculated based on an estimate that 156 in 1000 untreated children have a resolution) (moderate-certainty evidence). Both trials reported that there were no complications of surgery. However, the numbers of patients randomly allocated to surgery (19 and 14 patients respectively) were too small to detect potentially important complications such as haemorrhage.

Surgery probably results in a large overall reduction in the average number of episodes over the total length of follow-up (rate ratio 0.08 , $95 \% \mathrm{Cl} 0.05$ to 0.13 ), reducing the average frequency of PFAPA episodes from one every two months to slightly less than one every two years (moderate-certainty evidence). Surgery also likely reduces severity, as indicated by the length of PFAPA symptoms during these episodes. One study reported that the average number of days per PFAPA episode was 1.7 days after receiving surgery, compared to 3.5 days in the control group (moderate-certainty evidence). The evidence suggests that the proportion of patients requiring corticosteroids was also lower in the surgery group compared to those receiving no surgery (RR $0.58,95 \% \mathrm{Cl} 0.37$ to 0.92 ) (low-certainty evidence).

Other outcomes such as absence from school and quality of life were not measured or reported.

\section{Authors' conclusions}

The evidence for the effectiveness of tonsillectomy in children with PFAPA syndrome is derived from two small randomised controlled trials. These trials reported significant beneficial effects of surgery compared to no surgery on immediate and complete symptom resolution $(\mathrm{NNTB}=2)$ and a substantial reduction in the frequency and severity (length of episode) of any further symptoms experienced. However, the evidence is of moderate certainty (further research is likely to have an important impact on our confidence in the estimate of effect and may change the estimate) due to the relatively small sample sizes of the studies and some concerns about the applicability of the results. Therefore, the parents and carers of children with PFAPA syndrome must weigh the risks and consequences of surgery against the alternative of using medications. It is well established that children with PFAPA syndrome recover spontaneously and medication can be administered to try and reduce the severity of individual episodes. It is uncertain whether adenoidectomy combined with tonsillectomy adds any additional benefit to tonsillectomy alone.

\section{PLAIN LANGUAGE SUMMARY}

\section{Tonsillectomy for PFAPA syndrome (a rare cause of recurrent fever, mouth ulcers, sore throat and swollen neck glands)}

\section{Background}

Periodic fever, aphthous stomatitis, pharyngitis and cervical adenitis (PFAPA) syndrome is a rare cause of regular, repeated episodes of fever, sore throat and swollen neck glands in children. It is a diagnosis that needs confirmation by paediatricians working in centres with expertise in this condition and most children who suffer from repeated sore throats and tonsillitis will not have it. This review compared the clinical effectiveness and safety of removing the palatine tonsils (tonsillectomy), with and without removal of the adenoids, against non-surgical management of children with PFAPA syndrome.

\section{Study characteristics}

We searched for and included any randomised controlled trials published up to October 2019. We found two small randomised controlled trials, with a low risk of bias, comparing tonsillectomy or adenotonsillectomy against non-surgical interventions (total of 67 participants, with data from 65 analysed). One study (39 participants) used the adenotonsillectomy procedure in the intervention group and followed up patients for 18 months. This study applied stringent criteria for diagnosing PFAPA when recruiting patients. The other trial (28 participants) only removed the tonsils and followed up patients for up to six months. Less stringent recruitment criteria were applied and it was possible that patients with other types of recurrent sore throats might have been recruited and included in the trial. Neither study masked participants and investigators to the type of treatment received. Participants in the control groups of both studies received standard medical treatment.

\section{Key results}

The two trials showed that children with PFAPA are likely to benefit from tonsillectomy. The results showed that children who had surgery were about four times more likely to be free of PFAPA symptoms from the point of surgery until the end of the follow-up periods for these studies. There was an overall decrease in the number or frequency of PFAPA episodes experienced by the children in the surgery group. While the average child in the control arm had an average of one episode every two months, this was reduced to less than one-tenth of that; i.e. about one episode every two years among children who had surgery. In addition, the length of each episode was also shortened by an average of 1.8 days (reduced from an average of 3.5 days to 1.7 days per episode) for children who had surgery. 
Courses of corticosteroids can be used to treat episodes of symptoms in children with PFAPA. One trial reported that the proportion of children given a course of corticosteroids was lower in children who received surgery.

The trials reported no complications of surgery. However, these studies might be too small to detect important but rarer types of complications such as bleeding from the surgery. Other outcomes such as absence from school or quality of life were not reported.

\section{Certainty of evidence}

The certainty of the evidence is moderate (that is, further research is likely to have an important impact on our confidence in the estimates of effects and may change these estimates). The studies are very small. Studies with larger numbers of patients are required to estimate the effects more precisely. There is also some uncertainly about whether the effects observed in these studies can be replicated in most children with PFAPA for two reasons. It is unclear whether some children who did not have PFAPA had been included in the study that applied less stringent inclusion criteria for PFAPA diagnosis. Secondly, it is uncertain whether the treatment received in the control arms of the studies was adequate and represented current practice. 


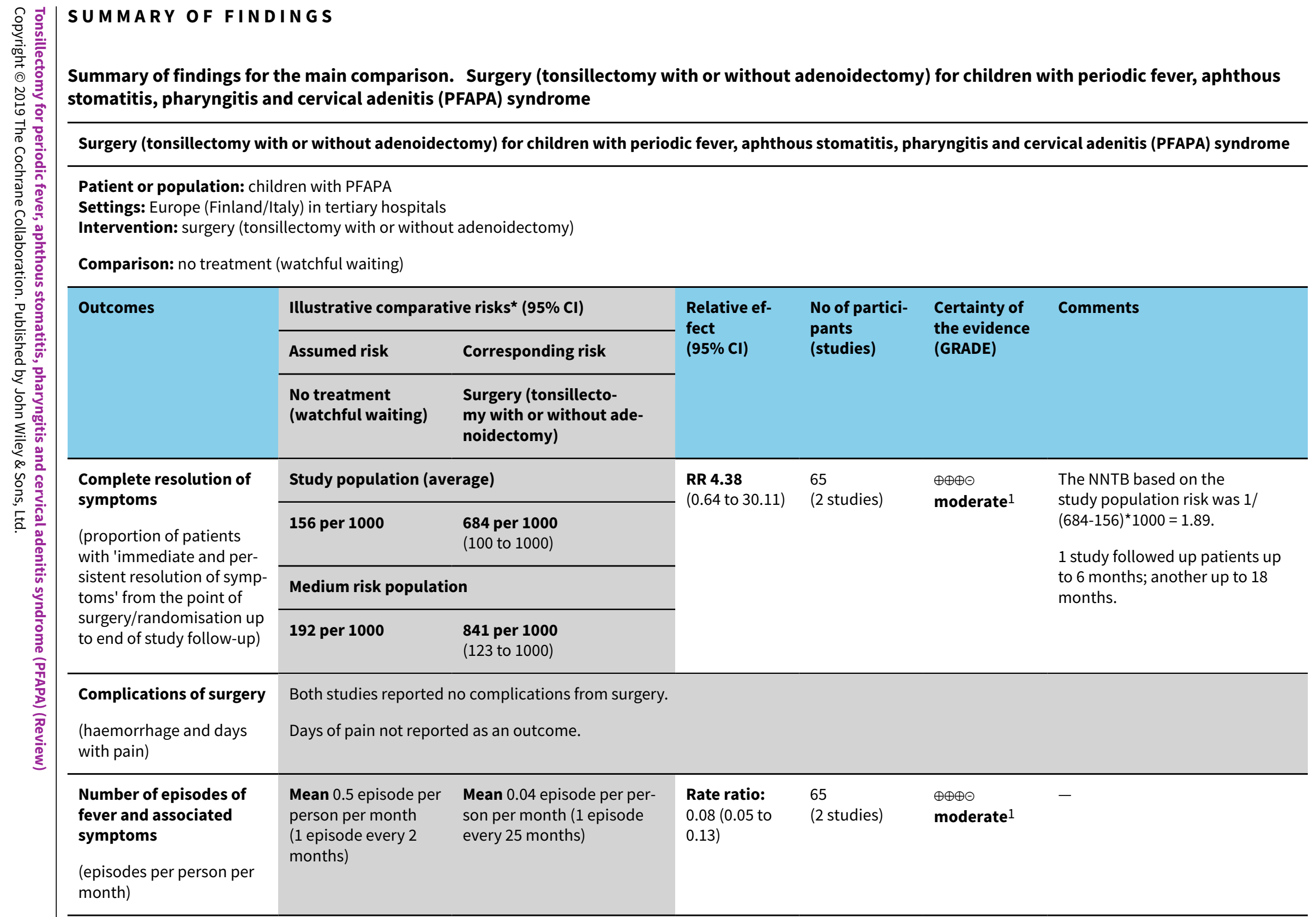




\begin{tabular}{|c|c|c|c|c|c|c|c|}
\hline 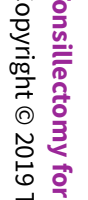 & $\begin{array}{l}\text { Severity of episodes } \\
\text { (number of days with } \\
\text { fever and the associated } \\
\text { symptoms (per episode)) }\end{array}$ & $\begin{array}{l}\text { Mean } 3.5 \text { (range } \\
\text { of } 2 \text { to } 6 \text { ) days per } \\
\text { episode }\end{array}$ & $\begin{array}{l}\text { Mean } 1.7 \text { (range of } 2 \text { to } 4 \text { ) } \\
\text { days per episode }\end{array}$ & $\begin{array}{l}\text { Mean differ- } \\
\text { ence: } 1.8 \text { days } \\
\text { per episode }\end{array}$ & $\begin{array}{l}39 \\
\text { (1 study) }\end{array}$ & $\begin{array}{l}\oplus \oplus \oplus \ominus \\
\text { moderate }^{1}\end{array}$ & $\begin{array}{l}\text { Study reported statistical sig- } \\
\text { nificance. Standard deviations } \\
\text { were not reported in the study } \\
\text { for average number of days per } \\
\text { episode. }\end{array}$ \\
\hline 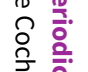 & & \multicolumn{2}{|c|}{ Study population (average) } & \multirow{2}{*}{$\begin{array}{l}\mathbf{R R} \mathbf{0 . 5 8} \\
(0.37 \text { to } 0.92)\end{array}$} & \multirow{2}{*}{$\begin{array}{l}39 \\
\text { (1 study) }\end{array}$} & \multirow{2}{*}{$\begin{array}{l}\oplus \oplus \ominus \ominus \\
\text { low } \mathbf{1 , 2}\end{array}$} & \multirow{2}{*}{$\begin{array}{l}\text { Review intended to report num- } \\
\text { ber of courses/patient, but these } \\
\text { data were not available in the } \\
\text { studies. }\end{array}$} \\
\hline 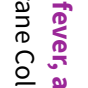 & $\begin{array}{l}\text { (proportion of patients us- } \\
\text { ing corticosteroids) }\end{array}$ & 900 per 1000 & $\begin{array}{l}\mathbf{5 2 2} \text { per } \mathbf{1 0 0 0} \\
\text { (333 to } 828)\end{array}$ & & & & \\
\hline 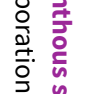 & $\begin{array}{l}\text { Absence or time off } \\
\text { school }\end{array}$ & \multicolumn{6}{|c|}{ None of the studies reported this } \\
\hline 皇 & Quality of life & \multicolumn{6}{|c|}{ None of the studies reported this } \\
\hline 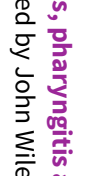 & \multicolumn{7}{|c|}{$\begin{array}{l}\text { *The basis for the assumed risk was the median risk in the control groups for "medium risk population" and for "study population", this was the average (i.e. total number } \\
\text { of participants with events divided by total number of participants included in the meta-analysis). The corresponding risk (and its } 95 \% \text { confidence interval) is based on the } \\
\text { assumed risk in the comparison group and the relative effect of the intervention (and its } 95 \% \mathrm{Cl} \text { ). } \\
\text { Cl: confidence interval; NNTB: number needed to treat to benefit; RR: risk ratio }\end{array}$} \\
\hline 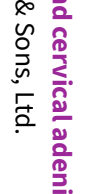 & \multicolumn{7}{|c|}{$\begin{array}{l}\text { GRADE Working Group grades of evidence } \\
\text { High certainty: Further research is very unlikely to change our confidence in the estimate of effect. } \\
\text { Moderate certainty: Further research is likely to have an important impact on our confidence in the estimate of effect and may change the estimate. } \\
\text { Low certainty: Further research is very likely to have an important impact on our confidence in the estimate of effect and is likely to change the estimate. } \\
\text { Very low certainty: We are very uncertain about the estimate. }\end{array}$} \\
\hline 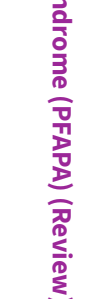 & \multicolumn{7}{|c|}{$\begin{array}{l}1 \text { We downgraded the certainty of the evidence by one level because of the small size of the studies and broad confidence intervals. There was also concern as to whether the } \\
\text { treatment received by the control group reflects current practice. The criteria for recruitment of patients into one of the studies was not stringent and could have included patients } \\
\text { who did not have PFAPA (Renko 2007). } \\
2 \text { We had additional concerns about the applicability of this outcome. Measuring the proportion of patients who had received steroids might not reflect the potential harms from } \\
\text { this alternative treatment, which increases with the number of courses used. The numbers used in our analysis were estimations from the percentages reported in the paper, } \\
\text { with the assumption that all patients randomised were included in the analysis. However, it is possible that not all participants were included in the study's analysis (i.e. there } \\
\text { was some loss of data). We therefore downgraded by an additional one level. }\end{array}$} \\
\hline
\end{tabular}




\section{B A C K G R O U N D}

Tonsillectomy is often performed for chronic or recurrent acute tonsillitis or sore throat. These are relatively common clinical conditions and important reasons for seeking medical attention and advice. Periodic fever, aphthous stomatitis, pharyngitis and cervical adenitis (PFAPA) syndrome is a much rarer and more unusual condition but one for which tonsillectomy is thought to be beneficial. The 2019 update of the AAO-HNS clinical practice guideline for tonsillectomy in children continues to recommend that children with recurrent throat infection who do not meet the main criteria for surgery should be assessed for modifying factors that may favour tonsillectomy; these include PFAPA (Mitchell 2019). This is an update of a Cochrane Review first published in 2010 and previously updated in 2014 (Burton 2010; Burton 2014b).

\section{Description of the condition}

PFAPA syndrome is a rare clinical syndrome, usually identified in children, and comprising those features described in its title. The original description is attributed to Marshall, Edwards, Butler and Lawton in 1987 (Marshall 1987). The same authors first used the acronym PFAPA and proposed a set of diagnostic criteria in 1989 (Marshall 1989), and they re-iterated these criteria in an often cited publication of 1999 (Thomas 1999). Case definition continues, however, to be an issue in this field. A more recently published large series of 105 patients, co-authored by a physician involved in some of the earliest studies of the condition, identified PFAPA patients using criteria which differed somewhat from the standard (Feder 2010).

The cause of PFAPA syndrome is unknown and it occurs sporadically. There are a number of related, but distinct, periodic fever syndromes in which underlying genetic abnormalities have been characterised. The periodicity has been described as 'clockwork' (Long 2007) (and episodes are therefore 'predictable' by the parents and carers of affected children), with episodes occurring every 30 days (range 14 to 50 ) and lasting four days (range two to seven) (Feder 2010).

In children whose condition resolves spontaneously, Feder 2010 reported the mean and median duration of symptoms as 33 and 24 months respectively (range 8 to 92 months).

\section{Description of the intervention}

Tonsillectomy is one of the most common surgical procedures performed in children. The procedure has been a controversial one historically and it remains so. Opinions vary greatly as to the relative risks and benefits of the surgery and the indications are equally controversial. It is generally accepted that tonsillectomy (with adenoidectomy, if necessary) is indicated in children with obstructive sleep apnoea. In many countries large numbers of patients who have recurrent acute tonsillitis, chronic tonsillitis or recurrent 'sore throats' also have their tonsils removed. The frequency and severity of 'infections' required to justify surgery vary considerably. The effectiveness of tonsillectomy for chronic/ recurrent acute tonsillitis and sore throat is the subject of another Cochrane Review by some of us (Burton 2014a).

Any benefit of tonsillectomy must offset the risks of surgery. These include those of the associated general anaesthesia and those specific to the procedure, for example bleeding immediately after surgery or in the 10- to 14-day period after surgery. Equally relevant are the natural history of the untreated disease (many children with PFAPA syndrome will 'grow out' of the condition as they get older) and the availability and effectiveness of non-surgical treatment to prevent or ameliorate symptomatic episodes. Medical treatment of PFAPA includes the use of corticosteroids for individual episodes or cimetidine for prophylaxis (Feder 2010). However, these treatments are not used in all countries (Renko 2008), and have not to our knowledge been evaluated in randomised controlled trials.

\section{How the intervention might work}

The cause of PFAPA is not known. The clinical features of periodicity and inflammation suggest that it may be a genetically regulated periodic fever, like other defined periodic fever syndromes. However, since tonsillectomy aborts the symptoms of PFAPA in many patients the inflammation is presumably driven from these lymphoid tissues. The inflammation might originate from dysregulated tonsillar cells directly or be initiated locally by a mediator from another tissue or a microbial stimulus. In either case removal of the tissues interrupts the inflammation.

\section{Why it is important to do this review}

Several non-randomised studies have suggested that tonsillectomy has a dramatic effect in children with PFAPA. Abramson reported the unexpected complete resolution of symptoms in four children after tonsillectomy in 1989 (Abramson 1989). Long has described two 'major stumbling blocks' in testing treatments for PFAPA: the small number of patients with the condition and the difficulties confirming the diagnosis (Long 2009). This last observation underlines the importance of examining the participants in any study and asking the question: do all these children really have PFAPA syndrome? Or does the study population comprise a more heterogeneous group including some with other types of pharyngitis or tonsillitis? Answers to these questions will have a critical impact on the applicability of the results. The small number of patients means that individual studies are likely to be small. Yet, if the treatment effect size is large, a clinically and statistically significant difference between treatment and control groups may be identifiable. Combining the results of more than one study in a meta-analysis may allow a smaller positive effect size to be demonstrated or increase the precision of the estimate of that effect size. This systematic review therefore examines the clinical effectiveness and safety of tonsillectomy (with or without adenoidectomy) for children with PFAPA syndrome.

\section{O B JECTIVES}

To assess the effectiveness and safety of tonsillectomy (with or without adenoidectomy) compared with non-surgical treatment in the management of children with PFAPA syndrome.

\section{METHODS}

\section{Criteria for considering studies for this review}

\section{Types of studies}

We included studies with the following design characteristics:

- Randomised controlled trials (RCTs). 


\section{Types of participants}

Children with a diagnosis of periodic fever, aphthous stomatitis, pharyngitis and cervical adenitis (PFAPA) syndrome made by specialists (paediatricians) based on standard diagnostic criteria.

\section{Types of interventions}

Tonsillectomy (with or without adenoidectomy) or tonsillotomy.

We included all different surgical methods of tonsillectomy (such as blunt dissection, bipolar electrocautery and coblation) in this review.

\section{The comparison was:}

- tonsillectomy (with or without adenoidectomy) or tonsillotomy versus non-surgical treatment.

Non-surgical treatment was defined as all forms of non-surgical treatment, such as no treatment (including active monitoring/ watchful waiting), analgesics and antipyretics, corticosteroids and cimetidine therapy. We intended to consider the different nonsurgical treatments as separate subgroups.

\section{Types of outcome measures}

We analysed the following outcomes in the review, but we did not use them as a basis for including or excluding studies.

\section{Primary outcomes}

- Proportion of children whose symptoms have completely resolved.

- Complications of surgery (haemorrhage and number of days of postoperative pain).

\section{Secondary outcomes}

- Number of episodes of fever and the associated symptoms.

- Severity of episodes, defined as the number of days with fever and the associated symptoms per episode.

- Use of corticosteroids, measured as the number of courses per patient.

- Absence or time off school.

- Quality of life (general health-related or disease-specific, as measured using a validated instrument).

Outcomes would ideally be assessed over a minimum period of 12 months, and preferably in the second and subsequent years after randomisation.

\section{Search methods for identification of studies}

The Cochrane ENT Information Specialist conducted systematic searches for randomised controlled trials and controlled clinical trials. There were no language, publication year or publication status restrictions. The date of the search was 15 October 2019.

\section{Electronic searches}

The Information Specialist searched:

- the Cochrane ENT Trials Register (searched via CRS Web 15 October 2019);
- the Cochrane Central Register of Controlled Trials (CENTRAL 2019, Issue 10) (searched via CRS Web 15 October 2019);

- PubMed (1945 to 15 October 2019);

- Ovid EMBASE (1974 to 15 October 2019);

- Ovid CAB Abstracts (1910 to 15 October 2019);

- EBSCO CINAHL (1982 to 15 October 2019);

- Web of Knowledge, Web of Science (1945 to 15 October 2019);

- LILACS (Latin American and Caribbean Health Science Information database), lilacs.bvsalud.org (searched 15 October 2019);

- ClinicalTrials.gov (searched via the Cochrane Register of Studies and clinicaltrials.gov 15 October 2019);

- World Health Organization (WHO) International Clinical Trials Registry Platform (ICTRP), www.who.int/ictrp (searched 15 October 2019).

In searches prior to 2019 we also searched KoreaMed, PakMediNet and IndMed (last search October 2013). In searches prior to 2012, we searched BIOSIS Previews 1926 to January 2010. In searches prior to 2007 we searched the NRR Archive 2000 to 2007.

The Information Specialist modelled subject strategies for databases on the search strategy designed for CENTRAL. Where appropriate, they were combined with subject strategy adaptations of the highly sensitive search strategy designed by Cochrane for identifying randomised controlled trials and controlled clinical trials (as described in the Cochrane Handbook for Systematic Reviews of Interventions Version 5.1.0, Box 6.4.b. (Handbook 2011). Search strategies for major databases including CENTRAL are provided in Appendix 1.

\section{Searching other resources}

We scanned the reference lists of identified publications for additional trials and contacted trial authors where necessary. In addition, the Information Specialist searched PubMed to retrieve existing systematic reviews relevant to this systematic review, so that we could scan their reference lists for additional trials. The Information Specialist also ran non-systematic searches of Google Scholar to retrieve grey literature and other sources of potential trials.

We did not perform a separate search for adverse effects. We considered adverse effects described in the included studies only.

\section{Data collection and analysis}

\section{Selection of studies}

Two review authors independently screened titles and abstracts of the studies obtained from the database searches and reviewed the full text of the potentially relevant titles and abstracts against the inclusion and exclusion criteria. We documented the exclusion of any studies from the review and described the reasons for exclusion in the Characteristics of excluded studies table. We resolved any differences over which studies to include or exclude by discussion and consensus.

\section{Data extraction and management}

In the first publication of this Cochrane Review (Burton 2010), two authors (MJB and JR) independently extracted data from the studies using standardised, pre-piloted forms. For this 2019 update, 
two new authors rechecked the data and, had additional studies been identified, we would have used the same methods to extract the data. We extracted data so as to allow an intention-to-treat analysis. Where data were missing, we contacted the trial authors to request further information or conducted an available case analysis if necessary.

\section{We extracted the following data items:}

- basic study design features (e.g. double-blind, parallel-group, randomised trial, cluster-randomised trial) and duration of study;

- setting (country, centre(s), tertiary centre/primary care, year etc);

- sample size; number randomised (total participants recruited into the study) and number completed;

- participant (baseline) characteristics (age, gender, other characteristics); inclusion and exclusion criteria;

- details of intervention and comparator; use of additional medication/treatment (common to both groups);

- outcomes: primary and secondary outcomes;

- funding sources and study author declarations of interest.

\section{Assessment of risk of bias in included studies}

In the first publication of this Cochrane Review (Burton 2010), two review authors (MJB and JR) undertook assessment of the risk of bias of the included trials independently, with the following taken into consideration, as guided by theCochrane Handbook for Systematic Reviews of Interventions (Handbook 2011):

- sequence generation;

- allocation concealment;

- blinding;

- incomplete outcome data; and

- reporting bias

- other sources of bias.

We used the Cochrane 'Risk of bias' tool, which involves describing each of these domains as reported in the trial and then assigning a judgement about the risk of bias of each domain: 'low', 'high' or 'unclear' risk of bias.

\section{Measures of treatment effect}

We proposed analysing the data according to the intention-to-treat principle, whereby all participants are analysed in the groups to which they were randomised.

We expressed dichotomous outcomes (e.g. proportion of patients with symptom resolution) as risk ratios (RR) and risk difference (RD) with 95\% confidence intervals (Cls). Additionally, we calculated the number needed to treat to benefit (NNTB) from the pooled measure of treatment effect.

Due to the nature of the condition (episodic), the intervention being evaluated may reduce the frequency of the episodes or resolve the episodes completely. Therefore, most of the outcomes are count data and we analysed these as rate data whenever possible (whenever time of follow-up was available). We proposed calculating the rate ratio of number of outcomes per person-month for count data whenever possible.
Where there were missing data or there was loss to follow-up, we planned an available case analysis.

\section{Unit of analysis issues}

We identified no studies with non-standard designs, such as crossover or cluster-randomised trials. Had we done so, we would have used the methods outlined in the Cochrane Handbook for Systematic Reviews of Interventions chapter 9.3 (Handbook 2011).

\section{Dealing with missing data}

In the case of missing data, we contacted the corresponding trial authors to obtain additional information. No imputations for missing data were pre-planned, apart from standard calculations to obtain SD values for continuous data as detailed in the Cochrane Handbook for Systematic Reviews of Interventions (Handbook 2011).

\section{Assessment of heterogeneity}

We assessed clinical heterogeneity (which may be present even in the absence of statistical heterogeneity) by examining the included trials for potential differences between studies in the types of participants recruited, interventions or control used and outcomes measured. We did not identify any specific subgroups for subgroup analysis a priori.

We also assessed statistical heterogeneity using the $\mathrm{Chi}^{2}$ test (with a significance level set at $\mathrm{P}<0.10$ ) and the $\mathrm{I}^{2}$ statistic, which calculates the percentage of variability that is due to heterogeneity rather than chance, with $\mathrm{I}^{2}$ values over $50 \%$ suggesting substantial heterogeneity (Handbook 2011).

\section{Assessment of reporting biases}

We planned to compare the outcomes reported in the trial against the protocols for the studies, whenever possible, to assess for reporting bias. If a sufficient number of studies had been available, we would have conducted more formal assessments using funnel plots.

\section{Data synthesis}

For dichotomous data, we analysed treatment differences as risk ratio (RR) with $95 \%$ confidence interval $(\mathrm{Cl})$ calculated using the Mantel-Haenszel method with a fixed-effect model and the generic inverse-variance method for the rate ratios. For dichotomous data, we calculated the number needed to treat to benefit (NNTB) using the results of the meta-analysis (which itself used risk ratio) based on an assumed baseline risk. This assumed baseline risk is typically either (a) the median of the risks of the control groups in the included studies, this being used to represent a 'medium-risk population' or, alternatively, (b) the average risk of the control groups in the included studies is used as the 'study population' (Handbook 2011). Should further studies be added in future updates it may also be appropriate to consider assumed baseline risk in (c) a low-risk population and (d) a high-risk population.

\section{Subgroup analysis and investigation of heterogeneity}

We did not plan or perform any subgroup analyses.

We assessed heterogeneity by visual inspection of the forest plots and consideration of the statistical tests for heterogeneity. We assessed statistical heterogeneity by considering the $\mathrm{Chi}^{2}$ test for 
significance at $\mathrm{P}<0.1$ or an 12 inconsistency statistic of more than $50 \%$ indicating significant heterogeneity.

We also planned to use a 'test of subgroup differences' to assess potential differences in effects between subgroups.

We used a fixed-effect meta-analysis where no heterogeneity was present. If statistical heterogeneity was detected but unresolved by subgroup or sensitivity analysis, then we employed a randomeffects (DerSimonian and Laird) model to provide a more conservative estimate of the effect.

\section{Sensitivity analysis}

We did not plan or perform any sensitivity analysis.

\section{Summary of findings and assessment of the certainty of the evidence}

Three authors (LYC, RV, MJB) independently used the GRADE approach to rate the overall certainty of evidence. The certainty of evidence reflects the extent to which we are confident that an estimate of effect is correct and we applied this in the interpretation of results. There are four possible ratings: high, moderate, low and very low. A rating of high certainty of evidence implies that we are confident in our estimate of effect and that further research is very unlikely to change our confidence in the estimate of effect. A rating of very low certainty implies that any estimate of effect obtained is very uncertain.

The GRADE approach rates evidence from RCTs which do not have serious limitations as high-certainty. However, several factors can lead to the downgrading of the evidence to moderate, low or very low. The degree of downgrading is determined by the seriousness of these factors:

- study limitations (risk of bias);

- inconsistency;

- indirectness of evidence;

- imprecision; and

- publication bias.

We included 'Summary of findings' tables for the comparison of tonsillectomy (with or without adenoidectomy) versus nonsurgical treatment, constructed according to the recommendations described in Chapter 10 of the Cochrane Handbook for Systematic Reviews of Interventions (Handbook 2011).

We included the following outcomes in the 'Summary of findings' table: complete resolution of symptoms (proportion of patients with 'immediate and persistent resolution of symptoms' from the point of surgery/randomisation up to end of study followup); complications of surgery (haemorrhage and days with pain); number of episodes of fever and associated symptoms (episodes per person per month); severity of episodes (number of days with fever and the associated symptoms (per episode)); use of corticosteroids (proportion of patients using corticosteroids); absence or time off school; and quality of life.

\section{RES U L T S}

\section{Description of studies}

See: Characteristics of included studies; Characteristics of excluded studies; Characteristics of ongoing studies.

\section{Results of the search}

This is an update of a Cochrane Review first published in 2010 and previously updated in 2014 (Burton 2010; Burton 2014b). The original searches in January 2010 retrieved 110 results. After removal of duplicates and an initial sift for relevance, we were left with three potentially relevant references (Garavello 2009; Pignataro 2009; Renko 2007). We excluded one as a nonrandomised prospective study (Pignataro 2009), leaving two studies that could be included in the review (Garavello 2009; Renko 2007).

From the previous updated searches (January 2010 to 30 October 2013) we retrieved a total of 82 additional records. Removing duplicates left 36. After screening titles and abstracts, we identified two additional potentially relevant studies (Peridis 2010a; Ridder 2011). These two studies were, however, excluded as nonrandomised cohort studies. As a consequence, no additional trials were identified for the 2014 update of this review. We did not identify any ongoing trials.

In October 2019 we updated the searches and retrieved a total of 174 records, which reduced to 80 after the removal of duplicates. Two authors independently screened the titles and abstracts of the 80 records using Covidence (Covidence 2019). We discarded 77 of these records and formally excluded three studies with reasons (see Excluded studies). We did not find any further studies that met the inclusion criteria; however, we did identify a new ongoing study (NCT03331497, see below and Characteristics of ongoing studies).

See Figure 1 for a PRISMA flow chart depicting the study search and selection process. 
Figure 1. Process for sifting search results and selecting studies for inclusion

\section{2 studies included in the 2014 version of review}




\section{Included studies}

Two unblinded, randomised controlled trials are included in this review (Garavello 2009; Renko 2007). Full details on methods, participants, interventions and outcomes are provided in the Characteristics of included studies table. We contacted the authors of both studies for further information about the methods and results of studies in October 2013, but we only obtained additional information from the authors of Renko 2007.

\section{Design}

Both studies were unblinded randomised controlled trials (RCTs).

\section{Setting}

Both studies were undertaken in European tertiary/university hospitals. Participants were recruited from three tertiary hospital in Oulu Finland between 1999 and 2003 (Renko 2007), and the ENT department of the University Hospital of Milano-Bicocca from 2003 to 2006 (Garavello 2009).

\section{Participants}

The studies included children aged between 1.5 and 14 years. The mean ages of the children were 4.1 (Renko 2007) and 5.1 (Garavello 2009) years. The studies differed in the diagnostic criteria used to define the participants as suffering from PFAPA syndrome.

The children included in Renko 2007 were characterised by a specific number of "PFAPA attacks" (at least five) and each attack needed to have been itself characterised by high fever ( $\geq$ $38.5^{\circ} \mathrm{C}$ ) of unknown origin. The attacks had to recur with "a typical, regular pattern" with "asymptomatic intervals of 2 to 5 weeks". Although any accompanying signs of aphthous stomatitis, pharyngitis and adenitis were "recorded", these features were not essential requirements of the diagnosis. In a subsequent letter the senior author clarified that "pharyngitis or tonsillitis caused by group A streptococcus was excluded on clinical grounds" and that "The diagnostic criteria presented by Thomas 1999 et al were not fulfilled in all our patients" (Renko 2008).

Garavello 2009 included children who had a diagnosis of PFAPA syndrome based on four criteria:

- Onset of disease in early childhood (before five years of age).

- Regular, recurring, abrupt episodes of fever lasting approximately five days, associated with constitutional symptoms and at least one of: aphthous stomatitis, pharyngitis or cervical adenitis in the absence of other signs of respiratory tract infection. These latter signs were present in the following proportions of participants: aphthous stomatitis - $61 \%$ of surgery group, $58 \%$ of controls; pharyngitis - $98 \%$ surgery, $97 \%$ controls; cervical adenitis - $89 \%$ surgery, $82 \%$ controls.

- Prompt remission of symptoms after corticosteroid administration and completely asymptomatic interval.

- Normal growth and development.

Children with cyclic neutropenia, other auto-inflammatory diseases and clinical and laboratory evidence of immunodeficiency, autoimmune disease or chronic infection were excluded.
Participants in Renko 2007 had on average 9.3 (range 4 to 20) episodes per year, while participants in Garavello 2009 had an average of 8.7 (range 4 to 12) episodes per year at baseline.

\section{Interventions}

The children in Renko 2007 received tonsillectomy (method unclear) within one month and in Garavello 2009 adenotonsillectomy (method unclear).

No details are given about the management of children in the control group of Renko 2007, but the author subsequently clarified that in Finland, where the study was performed, "cimetidine and prednisolone are not used for PFAPA ... and were not used in any of the patients in this series" (Renko 2008). Children in the control group were allowed tonsillectomy after six months if the symptoms persisted.

Garavello 2009 allowed children in both the control group and the surgical group to "use corticosteroids" and refers to this group receiving "expectant management". There is no indication of whether or not the control groups received prophylactic cimetidine.

\section{Outcomes}

Although symptom diaries were completed over a 12-month period in Renko 2007, results are presented at six months. The study period in Garavello 2009 was 18 months.

\section{Proportion of children whose symptoms have completely resolved}

Both studies reported (as a primary outcome measure) the proportion of patients experiencing resolution of their PFAPA symptoms, but different definitions were used:

- Renko 2007 defined it as "disappearance of fever episodes" six months after randomisation (counting the number of children without symptoms at the six-month follow-up).

- Garavello 2009 used the definition of "immediate and persistent resolution of symptoms" (counting only children whose symptoms resolved from the point of surgery/randomisation and had no recurrence within the 18-month follow-up).

Due to the differences in definitions used for symptom resolution outcomes, we contacted the authors to obtain more information for the 2014 update. We obtained more information from the authors of Renko 2007, but not from Garavello 2009.

\section{Complications of surgery (haemorrhage and number of days of postoperative pain)}

Both studies reported that no complications were experienced by patients receiving surgery.

\section{Number of episodes of fever and the associated symptoms}

Data are presented for both treatment and control groups on the number of "fever episodes compatible with periodic fever" per person-month at risk over the six-month follow-up period in Renko 2007. The absolute number of "PFAPA episodes" in both groups over 18 months is provided by Garavello 2009.

\section{Severity of episodes}

Garavello 2009 reported the mean number of days per episode among patients who still had symptoms after surgery (or 
randomisation, in the case of control group patients) until the end of follow-up.

\section{Use of corticosteroids}

Garavello 2009 reported on the proportion of patients who had received corticosteroids for each group, but not the number of courses required.

\section{Absence or time off school}

Neither study reported this outcome.

\section{Quality of life}

Neither study reported this outcome.

\section{Excluded studies}

Six studies were found to be non-randomised/retrospective cohort studies and we therefore excluded them from the review (Erdogan
2016; Ibáñez Alcalde 2017; Pignataro 2009; Peridis 2010a; Ridder 2011; Vigo 2014). See the Characteristics of excluded studies table.

\section{Ongoing studies}

We identified one ongoing study (NCT03331497). This is an openlabel randomised controlled trial comparing tonsillotomy with no intervention in children ( 1 to 12 years) with PFAPA syndrome. The estimated study completion date is May 2020.

\section{Risk of bias in included studies}

We judged both trials as at low risk of bias (Garavello 2009; Renko 2007). Details of the 'Risk of bias' assessment of the included trials are summarised in a 'Risk of bias' graph (Figure 2) and summary (Figure 3).

\section{Figure 2. 'Risk of bias' graph: review authors' judgements about each methodological quality item presented as} percentages across all included studies.

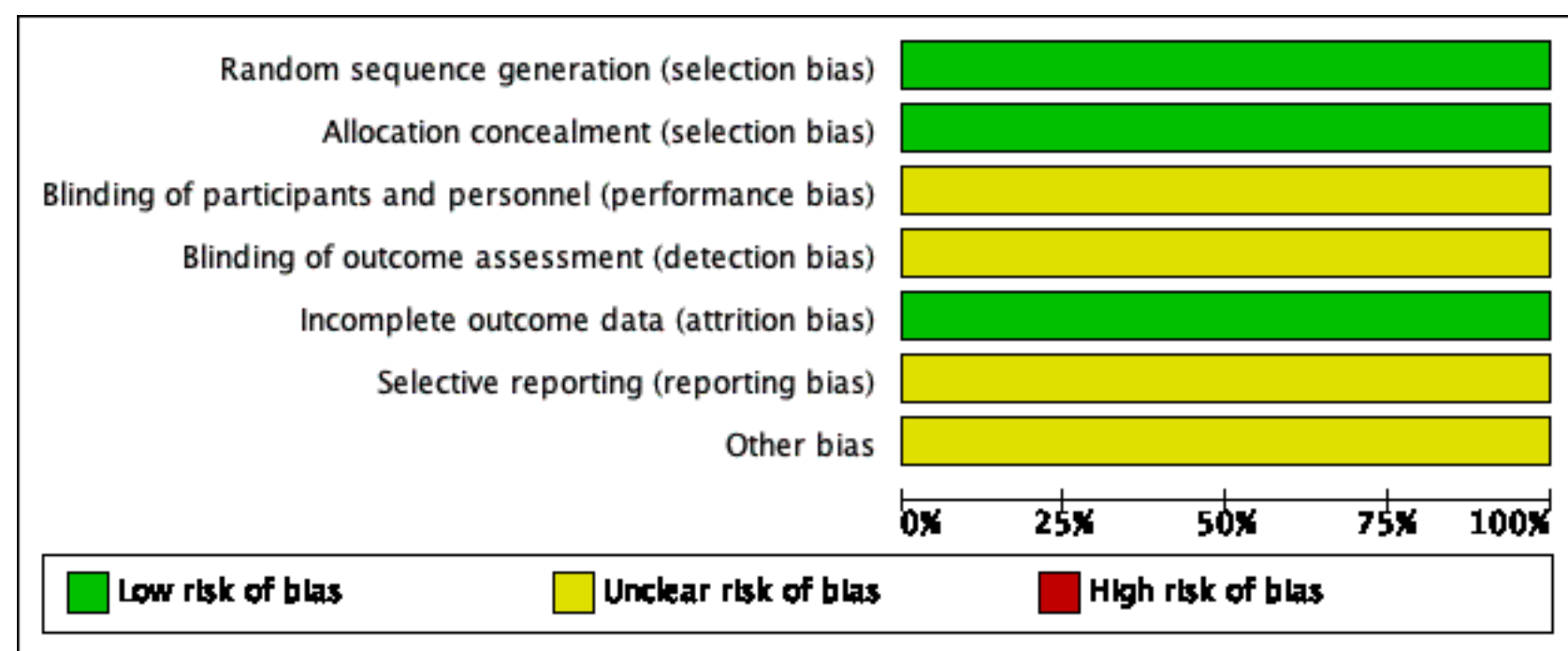


Figure 3. 'Risk of bias' summary: review authors' judgements about each methodological quality item for each included study.

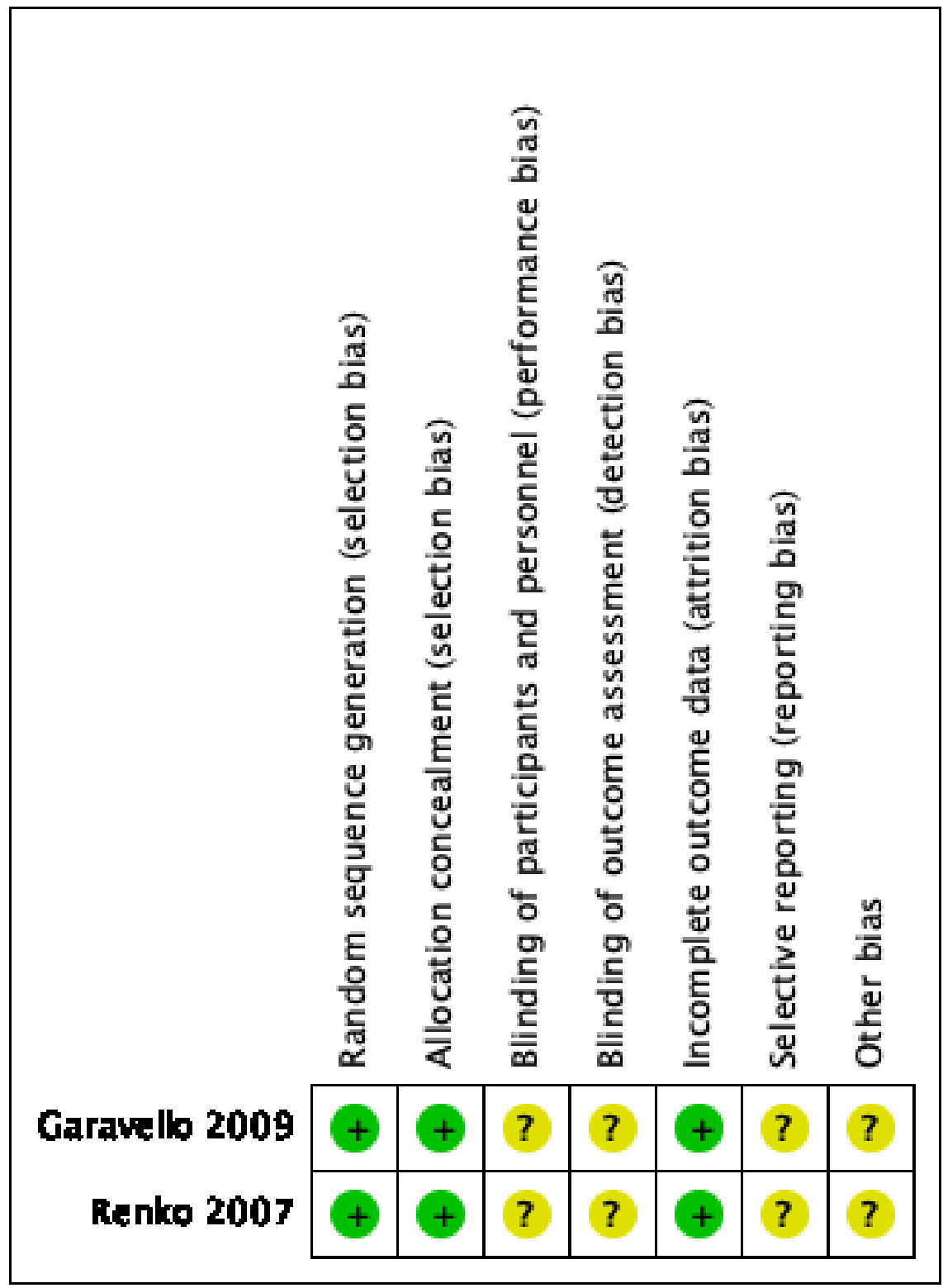

\section{Allocation}

One trial adequately described the method of random sequence generation and concealment of allocation (Garavello 2009). While this was unclear in the other trial, as no information was provided in the publication, we requested additional information on the method of random sequence generation and concealment of allocation and this was provided by the author of the trial; we subsequently judged the risk of selection bias to be low (Renko 2007).

\section{Blinding}

Neither of the trials used blinding. In this type of trial it is impossible for the surgeon, parent or child to be blind to the fact that the child has or has not had surgery. Using an episode of fever as an outcome measure is sensible and will tend to minimise bias, although a parent or carer may be biased in their decision as to whether or not to check the child's temperature. Therefore the risk of bias for blinding was unclear for both studies.

\section{Incomplete outcome data}

We judged the risk of attrition bias to be low. In one trial no children were lost to follow-up (Garavello 2009), while missing data were limited in the other trial (Renko 2007): 2/28 children (7\%) were not included in analyses at six months. These two children were equally distributed over the groups.

\section{Selective reporting}

We did not have access to study protocols and we did not have enough information to assess the risk of selective reporting bias. We noted that although Renko 2007 stated in the methods section that participants would be followed up for 12 months using patient 
diaries, only the six-month results were reported. We therefore judged the risk of bias from selective reporting to be unclear.

As there were only two studies, we could not conduct formal assessment using funnel plots.

\section{Other potential sources of bias}

In one trial there appeared to be a small imbalance in the number of children without any symptoms other than fever between the tonsillectomy group and the control group: seven (50\%) versus four (33\%), respectively (Renko 2007). This might have some influence on the results.

\section{Effects of interventions}

See: Summary of findings for the main comparison Surgery (tonsillectomy with or without adenoidectomy) for children with periodic fever, aphthous stomatitis, pharyngitis and cervical adenitis (PFAPA) syndrome

The main findings are reported in Summary of findings for the main comparison.

\section{Tonsillectomy (with or without adenoidectomy) versus non- surgical treatment}

\section{Primary outcomes}

\section{Proportion of children whose symptoms have completely resolved}

As described in the Included studies section, Garavello 2009 reported the number of patients who had "immediate and persistent resolution of PFAPA syndrome" after the surgery/ randomisation, which was sustained until the end of follow-up (at 18 months): $12 / 19$ in the surgery group and $1 / 20$ in the control group.

For the 2014 update, we could obtain data with the same definition from the authors of Renko 2007 for the six-month follow-up period (their longest available follow-up): 10/14 in the surgery group and $4 / 12$ in the control group. Despite the difference in the length of follow-up, we decided to pool these data in Analysis 1.1, since this measures the number of patients whose symptoms stopped immediately after surgery/randomisation.

However, it should be noted that the proportions of children who had "immediate and persistent symptom resolution" at six months follow-up in Garavello 2009 would probably be higher than (or equal to) the numbers used in Analysis 1.1 (which used the 18month follow-up data from Garavello 2009). It is possible that some children (from both arms) had symptom recurrence between six and 18 months.

The pooled risk ratio (RR) is 4.38 ( $95 \%$ confidence interval $(\mathrm{Cl}) 0.64$ to 30.11), which corresponds to a number needed to treat to benefit (NNTB) of two, if the average risks in the control groups of both studies (156 per 1000) are used as a baseline risk (Analysis 1.1). We observed substantial heterogeneity in this pooled risk ratio $\left(1^{2}=71 \%\right.$, $\mathrm{P}$ value $\left.=0.06\right)$. Heterogeneity as measured by the $1^{2}$ statistic appears to depend on the type of measure used. If the meta-analysis is undertaken using an odds ratio (OR $11.04,95 \% \mathrm{Cl}$ 1.77 to 69.08 ), the $\mathrm{I}^{2}$ value reduces to $44 \%$; if a risk difference is used, the $\mathrm{I}^{2}$ is $0 \%$ (RD $0.52,95 \% \mathrm{Cl} 0.32$ to 0.72 ). We graded the certainty of the evidence for this outcome as moderate.
Apart from the length of follow-up, the difference in recruitment criteria used could also have contributed to the heterogeneity. The risk in the control group was 5\% in Garavello 2009 and 33\% in Renko 2007.

The alternative way of defining and measuring resolution of symptoms was to look at number of patients who became 'symptom-free' at a certain time point.

- In Renko 2007, the number of patients who were symptom-free at six months was $14 / 14$ in the surgery group and $6 / 12$ in the control group.

- Garavello 2009 reported that all patients who received surgery were symptom-free at the end of the follow-up (18 months), but did not provide the numbers in the control group. No further information could be obtained from the authors.

Therefore, although we knew that all patients who received surgery in both studies were 'symptom-free' at the end of their respective follow-up periods, data for this outcome could not be analysed due to the lack of numbers provided for the control group in Garavello 2009.

\section{Complications of surgery (haemorrhage and number of days of postoperative pain)}

In both trials it was reported that there were "no complications" of tonsillectomy (Garavello 2009; Renko 2007). The number of days with postoperative pain was not reported in the studies.

\section{Secondary outcomes}

\section{Number of episodes of fever and associated symptoms}

Whilst neither study specifically reported on the severity of disease episodes, Renko 2007 reported the number of episodes of fever per person-month and we were able to calculate the equivalent data from Garavello 2009. The results from Renko 2007 were 0.05 episodes per person-month in the surgical group and 0.47 episodes per person-month in the control group, based on the six-month follow-up period ( 34 events in 12 children over six months $=34 / 72$ $=0.472$, not 0.44 as reported in paper), with a corresponding rate ratio of 0.10 ( $95 \% \mathrm{Cl} 0.04$ to 0.28 ).

Garavello 2009 reported the mean number of episodes of PFAPA during the 18-month study period. The mean ( \pm standard deviation) number of episodes was $0.7 \pm 1.2$ in the surgery group and $8.1 \pm 3.9$ in the control group. This was a statistically significant difference of 7.4 episodes ( $95 \% \mathrm{Cl}-9.19$ to -5.61 ). However, these numbers are slightly different from the numbers Garavello 2009 provided in Table II of their publication, which reported a total of 12 episodes in the intervention group versus 179 episodes in the control group during the 18 months of follow-up. We used the data provided in Table II of the paper and calculated rate data as follows: 0.04 episodes per person-month in the surgical group and 0.50 episodes per person-month in the control group, based on the 18-month follow-up period (rate ratio $0.07,95 \% \mathrm{Cl} 0.04$ to 0.13 ). When the results from the two studies are combined (Analysis 1.2), the summary rate ratio is $0.08(95 \% \mathrm{Cl} 0.05$ to 0.13$)\left(1^{2}=0 \%\right)$. This represents a $92 \%$ reduction in the number of episodes per patient per month in the intervention group, from an average of about one episode every two months to slightly less than one episode every two years. We graded the certainty of the evidence for this outcome as moderate. 
This decrease in frequency and 'severity' (see below) means that over 18 months the average number of days a child in the study would experience fever and associated symptoms was 1.1 days in the surgery group and 31.3 in the control group, i.e. 0.06 days per month in the surgery group versus 1.7 days per month in the control group.

\section{Severity of episodes}

Garavello 2009 reported the mean number of days per episode among patients who still had symptoms after surgery (or randomisation, in the case of control group patients) until the end of follow-up. This was 1.7 days (range 2 to 4 ) in the surgery group versus 3.5 days (range 2 to 5 ) in the control group (moderatecertainty evidence).

\section{Use of corticosteroids}

Neither of the studies reported the number of courses of corticosteroids used.

Garavello 2009 reported that $50 \%$ of patients in the tonsillectomy group and $88 \%$ in the control group received corticosteroids, but it was unclear how many patients were included in the analysis out of the 19 recruited into the surgery arm and the 20 in the control arm. Under the assumption that all patients had been included in the analysis, this would work out as about 10/19 (53\%) in the tonsillectomy group and $18 / 20(90 \%)$ in the control group (RR $0.58,95 \% \mathrm{Cl} 0.37$ to 0.92 ). However, it is likely that not all patients were included in the study authors' reporting of percentages. We therefore also tested whether other possible values, such as '8/16 (50\%) versus 13/15 (88\%)', could be derived from these percentages. We found that these did not affect the RR and only widened the confidence intervals slightly $( \pm 0.06)$. We graded the certainty of the evidence for this outcome as low.

\section{Absence or time off school}

Neither of the studies reported this outcome (Garavello 2009; Renko 2007).

\section{Quality of life}

Neither of the studies reported this outcome (Garavello 2009; Renko 2007).

\section{DISCUSSION}

\section{Summary of main results}

Current evidence, which is derived from two small, non-blinded randomised controlled trials (RCTs), suggests that children with periodic fever, aphthous stomatitis, pharyngitis and cervical adenitis (PFAPA) syndrome likely experience less fever and less severe episodes after surgery compared to those receiving no surgery. The risk ratio (RR) for immediate and persistent resolution of symptoms up to the end of study follow-up periods was more than four times higher in the group receiving surgery (RR 4.38, $95 \%$ confidence interval $(\mathrm{Cl}) 0.64$ to 30.11 ). This corresponds to an absolute reduction in risk of about $50 \%$ and number needed to treat to benefit (NNTB) of two. By the end of follow-up, both studies reported that all patients had complete resolution in the surgery group.

Surgery probably results in a significant decrease in the rate of PFAPA episodes (rate ratio $0.08,95 \% \mathrm{Cl} 0.05$ to 0.13 ). In addition, surgery also seemed to improve the severity of PFAPA episodes; the average number of days per episode decreased from 3.5 days to 1.7 days in one of the studies (Garavello 2009). The same study also reported a decrease in the proportion of patients requiring corticosteroid treatment, but did not document the number of courses required by these patients.

Both studies reported that there were no complications of surgery, but these studies might be too small to detect rarer, but important, complications such as haemorrhage. The studies also did not report other important outcomes, such as absence from school or quality of life.

\section{Overall completeness and applicability of evidence}

PFAPA syndrome is a rare condition so perhaps it is not surprising that only two small randomised controlled trials have evaluated the effectiveness of tonsillectomy (with or without adenoidectomy) in this condition. There were a total of 67 participants randomised in these studies and data from 65 participants were available for analysis.

These studies reported results for six months (Renko 2007) and up to 18 months (Garavello 2009), respectively. We could only obtain and analyse the number of patients who no longer had symptoms from the point of surgery up to the end of follow-up (immediate and persistent resolution of symptoms), and we could not analyse the number of patients who were no longer symptomatic at the end of follow-up. Garavello 2009 reported "immediate and complete resolution of PFAPA syndrome" after surgery and reported that all 19 participants in the surgery group had complete resolution of symptoms by the end of follow-up ( 18 months). However, this study did not report how many participants in the control group also had complete resolution.

Although the data suggested that children who underwent surgery were more likely to be completely free of symptoms and those who still had symptoms had less prolonged episodes, it is unclear whether these advantages still persisted after 18 months. It is recognised that there is a spontaneous recovery rate and Feder 2010 reports a $20 \%$ rate, with a mean time to resolution of 33.2 months (range 8 to 92 months). The survey by Thomas 1999 followed up 83 patients of whom $34(41 \%)$ had stopped having episodes after a mean of 4.5 years of illness.

Was the treatment provided to the control groups of these studies adequate? In the Garavello 2009 study, it has been suggested that the 'expectant treatment' with oral corticosteroids given to the control group was not adequate (Bharti 2010) and that these control patients should have been treated more 'actively'. The adequacy of the treatment provided to those in the control group in the Renko 2007 study has also been criticised (Spalding 2008). However, the greatest criticism has been levelled at the diagnostic inclusion criteria with Hofer 2008, Pignataro 2009 and Spalding 2008 suggesting that not all the children in the Renko 2007 study had classical PFAPA.

It is also uncertain whether adenoidectomy combined with tonsillectomy adds any additional benefit to tonsillectomy alone. Garavello 2009 performed adenotonsillectomy while Renko 2007 only removed the tonsils. The currently available data are insufficient to undertake a meaningful sensitivity analysis to compare the results of these two types of surgery. 


\section{Quality of the evidence}

We considered the certainty of the evidence (our confidence in the estimate of effects) for the key domains using the GRADE criteria: we assessed study limitations, indirectness, inconsistency, imprecision and other issues such as outcome reporting bias for each outcome (Balshem 2011).

Both studies were small and we judged the risk of bias to be low.

For the outcome of complete resolution of symptoms after surgery, the certainty of evidence was moderate (further research is likely to have an important impact on our confidence in the estimate of effect and may change the estimate). A few factors contributed to this uncertainty: the sample sizes of the studies were small and there were some concerns about the applicability of the results to daily practice. One trial may have included children that did not have classical PFAPA (due to lack of stringent diagnostic inclusion criteria) and the treatment received in both control groups does not reflect current practice, which may have resulted in an overestimation of the relative efficacy of surgery.

\section{Potential biases in the review process}

Apart from the differences in patient recruitment criteria and risks of biases from study methodologies, the two studies also differed in the nature of the surgical intervention: tonsillectomy (Renko 2007) versus adenotonsillectomy (Garavello 2009). It is not possible to draw conclusions safely about the relative merits of one versus the other from the data provided (although some have tried to do so Bharti 2010). The combined procedure potentially removes a larger proportion of the tissue comprising Waldeyer's ring of lymphoid tissue. If the presence or severity of PFAPA syndrome is in some way proportional to the volume of pharyngeal lymphoid tissue, it might be expected that adenotonsillectomy would be better than tonsillectomy alone. From the practical surgical point of view there is a difference in 'risk' between the procedures in terms of operative time and postoperative morbidity, but this risk is very modest and most ENT surgeons consider it to be negligible.

Given the differences between the two study populations and the intervention, should the results be combined? Overall, the studies agree in their direction of effect for the outcomes reported and our a priori plan was to combine them, and investigate any heterogeneity should that be demonstrated.

For the primary outcome 'proportion of children whose symptoms have completely resolved' (based on 'immediate and complete resolution of symptoms' after surgery/randomisation), we observed that the degree of heterogeneity as measured by the $1^{2}$ statistic depended on the choice of summary statistic used. There was large variation in the baseline risk of the control groups (5\% risk in Garavello 2009 versus 50\% in Renko 2007).

\section{Agreements and disagreements with other studies or reviews}

A systematic review conducted before the publication of the RCTs we have included in this review argued that tonsillectomy should not be used for patients with PFAPA (Leong 2006). The best evidence they found at the time of their review came from six retrospective reviews of case notes. The resolution rate for patients who had tonsillectomy ranged from $0 \%$ to $100 \%$. Despite an overall success rate of more than $70 \%$ across the studies, it was felt that the evidence was too poor to justify the risk for a condition that could be treated medically or would resolve spontaneously. The RCTs included in this review provide further evidence that surgery is associated with a high rate of resolution, and provide better quality evidence to justify the procedure.

We identified another review that included a variety of study types (Peridis 2010b). However, we found a number methodological problems with the review and judged its overall quality to be low.

The American Academy of Otolaryngology - Head \& Neck Surgery updated their clinical practice guideline for tonsillectomy in children in 2019 (Mitchell 2019). This guideline continues to recommend that children with recurrent throat infection who do not meet the main criteria for surgery should be assessed for modifying factors that may favour tonsillectomy; these include PFAPA. This guidance is based on the evidence from earlier versions of this Cochrane Review and the two included RCTs.

Although both studies in this review reported no complications observed for patients undergoing surgery, this may be because the studies were too small to capture these less common events. There are risks of primary and secondary haemorrhage, best estimated (from the UK National Tonsillectomy Audit) at $0.6 \%$ and $3 \%$ respectively (BAO-HNS/RCSENG 2005). In addition, surgery involves the risks associated with any procedure conducted under general anaesthesia, a period in hospital (usually a day or one day and one night) and a postoperative recovery period characterised by sore throat requiring oral analgesics and lasting, in children, for several days. The child must be away from school or nursery during this period.

A new randomised controlled trial is in progress (NCT03331497); this open-label study is comparing tonsillotomy with no intervention in children with PFAPA syndrome and has an estimated completion date of May 2020. Future updates of this review will assess this study.

\section{AUTHORS' CONCLUSIONS}

\section{Implications for practice}

Tonsillectomy appears to be a useful treatment option in the management of children with periodic fever, aphthous stomatitis, pharyngitis and cervical adenitis (PFAPA) syndrome, based on moderate-certainty evidence. It is important to emphasise that PFAPA syndrome is a specific disorder with well-described diagnostic criteria. Whilst the findings of this review might reasonably be applicable to children with this disorder they may not be generalisable to children with similar or related disorders with 'looser' diagnostic criteria. As many ENT surgeons will describe seeing children with 'recurrent tonsillitis' or 'severe sore throats', whose health has improved dramatically following tonsillectomy, the question arises as to whether some of these children might have been undiagnosed sufferers from PFAPA syndrome.

Overall, surgery involves the risks associated with any procedure conducted under general anaesthesia, a period in hospital (usually a day or one day and one night), and a postoperative recovery period characterised by sore throat requiring oral analgesics and lasting, in children, for several days and leading to time off school or nursery during this period. Therefore, the parents and carers of 
children with PFAPA must weigh (1) the risks and consequences of surgery (hospitalisation, the general and specific surgical risks, a predictable period of postoperative pain and time away from school/nursery) against the alternative of (2) a finite period of recurrent episodes of disease at predictable intervals potentially requiring time off school and the regular use of medication. The benefits and risks of surgery must be considered in the context of the natural history of the disease and it is necessary to look beyond the period studied in the individual trials.

\section{Implications for research}

In this review a positive treatment effect has been demonstrated but the estimate of the effect size is not precise. Further studies are likely to improve precision, but may be thought unnecessary due to the large effect sizes observed in these trials.

In the previous version of this review we said: "Previous trials of children severely affected by tonsillitis (such as those by Paradise 1984) may have included (unwittingly or otherwise) children with PFAPA syndrome and this may have implications for interpretation of the results of those studies. Might these children, now identified as having PFAPA, represent a subgroup of all children diagnosed with 'recurrent tonsillitis' who benefit particularly from tonsillectomy?" We now believe this is unlikely, as the characteristic nature and very regular timing of PFAPA episodes makes the conditions readily distinguishable.
If further research is undertaken, a trial may be designed in such a way that it is possible to determine whether or not adenotonsillectomy or tonsillectomy alone are equally effective. We also recommend only including patients who fulfil strict diagnostic criteria for PFAPA, pre-defining the type of non-surgical (medical) treatment(s) used in the control arms and assessing both short- (less than six months) and long-term (up to two years) outcomes.

\section{ACKNOWLEDGEMENTS}

We gratefully acknowledge the assistance received from the staff at the Cochrane ENT editorial base in Oxford and gratefully thank Samantha Cox and Gemma Sandberg for their support with the search strategy and searches. We would also like to thank the peer reviewers, Mr William Mckerrow and Dr Andrew Riordan, and editors for their valuable feedback, and the study authors (Marjo Renko) for responding to our queries.

This project was supported by the National Institute for Health Research, via Cochrane Infrastructure, Cochrane Programme Grant or Cochrane Incentive funding to Cochrane ENT. The views and opinions expressed therein are those of the authors and do not necessarily reflect those of the Systematic Reviews Programme, NIHR, NHS or the Department of Health. 
R E F E R E N C E S

\section{References to studies included in this review}

Garavello 2009 \{published data only\}

Garavello W, Gaini RM. Reply. Journal of Pediatrics 2010;156(4):690.

* Garavello W, Romagnoli M, Gaini RM. Effectiveness of adenotonsillectomy in PFAPA syndrome: a randomized study. Journal of Pediatrics 2009;155(2):250-3.

\section{Renko 2007 \{published and unpublished data\}}

Renko M, Salo E, Putto-Laurila A, Saxen H, Mattila PS, Luotonen J, et al. A randomized, controlled trial of tonsillectomy in periodic fever, aphthous stomatitis, pharyngitis, and adenitis syndrome. Journal of Pediatrics 2007;151(3):289-92.

\section{References to studies excluded from this review}

Erdogan 2016 \{published data only\}

Erdogan F, Kulak K, Öztürk O, İpek iÖ, Ceran Ö, Seven H. Surgery vs medical treatment in the management of PFAPA syndrome: a comparative trial. Paediatrics and International Child Health 2016;36(4):270-4.

\section{Ibáñez Alcalde 2017 \{published data only\}}

Ibáñez Alcalde ML, Caldevilla Asenjo L, Calvo Rey C, GarcíaMon Marañés F, Blázquez Gamero D, Saavedra Lozano J, et al. Characteristics and disease course in a cohort of children with PFAPA syndrome in the community of Madrid, Spain. Reumatología Clinica 2017 Dec 8 [Epub ahead of print]. [DOI: https://doi.org/10.1016/j.reuma.2017.10.015]

\section{Peridis 2010a \{published data only\}}

Peridis S, Koudoumnakis E, Theodoridis A, Stefanaki K, Helmis G, Houlakis M. Surgical outcomes and histology findings after tonsillectomy in children with periodic fever, aphthous stomatitis, pharyngitis, and cervical adenitis syndrome. American Journal of Otolaryngology 2010;31:472-5.

\section{Pignataro 2009 \{published data only\}}

Pignataro L, Toretta A, Pietrogrande MC, Dellepiane RM, Pavesi P, Bossi A, et al. Outcome of tonsillectomy in selected patients with PFAPA syndrome. Archives of Otolaryngology Head and Neck Surgery 2009;135:548-53.

\section{Ridder 2011 \{published data only\}}

Ridder GJ, Onderka CE. Benefits and importance of tonsillectomy in children and youth with PFAPA syndrome [Nutzen und Wertigkeit der Adeno-Tonsillektomie bei Kindern und Jugendlichen mit PFAPA-Syndrom]. Laryngo- RhinoOtologie 2011;90:609-16.

\section{Vigo 2014 \{published data only\}}

Vigo G, Martini G, Zoppi S, Vittadello F, Zulian F. Tonsillectomy efficacy in children with PFAPA syndrome is comparable to the standard medical treatment: a long-term observational study. Clinical and Experimental Rheumatology 2014;32(4 Suppl 84):S156-9.

\author{
References to ongoing studies \\ NCT03331497 \{published data only\} \\ NCT03331497. Tonsillotomy or follow-up in PFAPA syndrome. \\ https://clinicaltrials.gov/ct2/show/NCT03331497 (first received \\ 6 November 2017).
}

\section{Additional references}

\section{Abramson 1989}

Abramson JS, Givner LB, Thompson JN. Possible role of tonsillectomy and adenoidectomy in children with recurrent fever and tonsillopharyngitis. Pediatric Infectious Disease Journal 1989;8(2):119-20.

\section{Balshem 2011}

Balshem H, Helfand M, Schunemann HJ, Oxman AD, Kunz R, Brozek J, et al. GRADE guidelines: 3. Rating the quality of evidence. Journal of Clinical Epidemiology 2011;64(4):401-6. [PUBMED: 21208779]

\section{BAO-HNS/RCSENG 2005}

British Association of Otorhinolaryngologists - Head and Neck Surgeons Comparative Audit Group \& Clinical Effectiveness Unit, The Royal College of Surgeons of England. National Prospective Tonsillectomy Audit: FINAL REPORT of an audit carried out in England and Northern Ireland between July 2003 and September 2004. http://www.rcseng.ac.uk/ publications/docs/national_prospective.html/view? searchterm=tonsillectomy\%20audit May 2005 (accessed June 2010).

\section{Bharti 2010}

Bharti B, Bharti S. Randomized trial of adenotonsillectomy versus expectant treatment in PFAPA (periodic fever, aphthous stomatitis, pharyngitis, cervical adenitis) syndrome: is the impasse over?. Journal of Pediatrics 2010;156(4):689-90.

\section{Burton 2014a}

Burton MJ, Glasziou PP, Chong LY, Venekamp RP. Tonsillectomy or adenotonsillectomy versus non-surgical treatment for chronic/recurrent acute tonsillitis. Cochrane Database of Systematic Reviews 2014, Issue 11. [DOI: 10.1002/14651858.CD001802.pub3]

\section{Covidence 2019 [Computer program]}

Veritas Health Innovation. Covidence. Melbourne, Australia: Veritas Health Innovation, accessed 2 May 2019.

\section{Feder 2010}

Feder HM, Salazar JC. A clinical review of 105 patients with PFAPA (a periodic fever syndrome). Acta Paediatrica 2010;99(2):178-84

Handbook 2011

Higgins JPT, Green S (editors). Cochrane Handbook for Systematic Reviews of Interventions Version 5.1.0 [updated 
March 2011]. The Cochrane Collaboration, 2011. Available from www.cochrane-handbook.org.

\section{Hofer 2008}

Hofer MF. Cured by tonsillectomy: was it really a PFAPA syndrome?. Journal of Pediatrics 2008;153(2):298.

\section{Leong 2006}

Leong SC, Karkos PD, Apostolidou MT. Is there a role for the otolaryngologist in PFAPA syndrome? A systematic review. International Journal of Pediatric Otorhinolaryngology 2006;70(11):1841-5. [PUBMED: 16908073]

\section{Long 2007}

Long SS. Tonsillectomy as treatment of PFAPA syndrome [comment]. Journal of Pediatrics 2007;151(3):A3.

\section{Long 2009}

Long SS. Tonsillectomy for management of PFAPA. Journal of Pediatrics 2009;155(2):A1.

\section{Marshall 1987}

Marshall GS, Edwards KM, Butler J, Lawton AR. Syndrome of periodic fever, pharyngitis, and aphthous stomatitis. Journal of Pediatrics 1987;110:43-6.

\section{Marshall 1989}

Marshall GS, Edwards KM, Lawton AR. PFAPA syndrome. Pediatric Infectious Disease Journal 1989;8(9):658-9.

\section{Mitchell 2019}

Mitchell RB, Archer SM, Ishman SL, Rosenfeld RM, Coles S, Finestone SA, et al. Clinical practice guideline: tonsillectomy in children (update). Otolaryngology - Head \& Neck Surgery 2019;160(1 Suppl):S1-42. [DOI: 10.1177/0194599818801757]

\section{Paradise 1984}

Paradise JL, Bluestone CD, Bachman RZ, Colborn DK, Bernard BS, Taylor FH, et al. Efficacy of tonsillectomy for recurrent throat infection in severely affected children. New

\section{CHARACTERISTICS OF STUDIES}

Characteristics of included studies [ordered by study ID]
England Journal of Medicine 1984;310(11):674-83. [PUBMED: 6700642 ]

\section{Peridis 2010b}

Peridis S, Pilgrim G, Koudoumnakis E, Athanasopoulos I, Houlakis M, Parpounas K. PFAPA syndrome in children: a metaanalysis on surgical versus medical treatment. International Journal of Pediatric Otorhinolaryngology 2010;74(11):1203-8. [PUBMED: 20832871]

\section{Renko 2008}

Renko M. Reply. Journal of Pediatrics 2008;152(5):743.

\section{Spalding 2008}

Spalding SJ, Hashkes PJ. The role of tonsillectomy in management of periodic fever, aphthous stomatitis, pharyngitis, and adenopathy: unanswered questions. Journal of Pediatrics 2008;152(5):742.

\section{Thomas 1999}

Thomas KT, Feder HM, Lawton AR, Edwards KM. Periodic fever syndrome in children. Journal of Pediatrics 1999;135(1):15-21.

\section{References to other published versions of this review Burton 2010}

Burton MJ, Pollard AJ, Ramsden JD. Tonsillectomy for periodic fever, aphthous stomatitis, pharyngitis and cervical adenitis syndrome (PFAPA). Cochrane Database of Systematic Reviews 2010, Issue 9. [DOI: 10.1002/14651858.CD008669]

\section{Burton 2014b}

Burton MJ, Pollard AJ, Ramsden JD, Chong L-Y, Venekamp RP. Tonsillectomy for periodic fever, aphthous stomatitis, pharyngitis and cervical adenitis syndrome (PFAPA). Cochrane Database of Systematic Reviews 2014, Issue 9. [DOI: 10.1002/14651858.CD008669.pub2]

* Indicates the major publication for the study

\section{Garavello 2009}

\begin{tabular}{ll}
\hline Methods & Non-blinded, parallel-group, randomised controlled trial with 18 months duration of follow-up \\
\hline Participants & Setting: ENT department of University Hospital of Milano-Bicocca (Italy) between 2003 and 2006 \\
Sample size: & Number randomised: 39 \\
- Number completed: 39 \\
Participant (baseline) characteristics: \\
- Age: 2 to 13 years \\
- Gender: number male 9 (47\%) tonsillectomy group; 7 (35\%) control group
\end{tabular}


- Baseline characteristics balanced. * Signs of criterion 2 (below) were present in the following proportions of participants: aphthous stomatitis - $61 \%$ of surgery group, $58 \%$ of controls; pharyngitis - $98 \%$ surgery, $97 \%$ controls; cervical adenitis - $89 \%$ surgery, $82 \%$ controls.

\section{Inclusion criteria:}

Met the following diagnostic criteria for PFAPA syndrome:

1. Onset of disease in early childhood (before 5 years of age)

2. Regularly recurring, abrupt episodes of fever lasting approximately 5 days associated with constitutional symptoms and at least 1 of the following: aphthous stomatitis, pharyngitis and cervical adenitis, in the absence of other signs of respiratory tract infection *

3. Prompt remission of symptoms after corticosteroid administration and completely asymptomatic interval

4. Normal growth and development

\section{Exclusion criteria:}

- Cyclic neutropenia, as assessed by serial neutrophil counts before, during and after a symptomatic episode (twice a week from one episode to the other)

- Other auto-inflammatory syndromes such as familial Mediterranean fever, hyperimmunoglobulinaemia D syndrome, Behcet disease, as assessed by family history and by the absence of typical clinical features and laboratory findings (IgD, gene analysis)

- Clinical and laboratory evidence of immunodeficiency, autoimmune disease or chronic infection

Interventions

\section{Intervention group:}

- Adenotonsillectomy (method not described); $N=19$ ( $N=19$ included in analysis at 6 months)

\section{Comparator group:}

- Watchful waiting (medical treatment); $N=20$ ( $N=20$ included in analysis at 6 months)

\section{Use of additional medication/treatment (common to both groups):}

- Use of corticosteroids was allowed

Outcomes Primary outcome:

- Proportion of patients experiencing immediate and persistent resolution of symptoms during the 18month study period

\section{Secondary outcome:}

- Number of PFAPA episodes during follow-up, resolution of symptoms over time

\begin{tabular}{|c|c|c|}
\hline Funding sources & \multicolumn{2}{|l|}{ Not stated } \\
\hline Declarations of interest & \multicolumn{2}{|c|}{ "The authors declare no conflicts of interest" } \\
\hline \multirow[t]{2}{*}{ Notes } & \multicolumn{2}{|c|}{ Proportion of children in treatment group that did not receive surgery: not described } \\
\hline & \multicolumn{2}{|c|}{ Proportion of children in control group electing for surgical treatment: $0 / 20(0 \%)$} \\
\hline \multicolumn{3}{|l|}{ Risk of bias } \\
\hline Bias & Authors' judgement & Support for judgement \\
\hline $\begin{array}{l}\text { Random sequence genera- } \\
\text { tion (selection bias) }\end{array}$ & Low risk & Computer-generated random number list \\
\hline
\end{tabular}


Garavello 2009 (Continued)

Allocation concealment Low risk Sealed, opaque envelopes were prepared by an independent researcher not (selection bias) engaged in the study

Blinding of participants

Unclear risk

No blinding: unclear if this could have affected treatment for the control arm and personnel (performance bias)

All outcomes

Blinding of outcome as-
$\begin{aligned} & \text { sessment (detection bias) } \\ & \text { All outcomes }\end{aligned}$$\quad \begin{aligned} & \text { No blinding, but measurement for the main outcomes of PFAPA resolution un- } \\ & \text { likely to be affected by blinding }\end{aligned}$

All outcomes

\begin{tabular}{lll}
$\begin{array}{l}\text { Incomplete outcome data } \\
\text { (attrition bias) } \\
\text { All outcomes }\end{array}$ & Low risk & No loss to follow-up or missing outcome data \\
\hline $\begin{array}{l}\text { Selective reporting (re- } \\
\text { porting bias) }\end{array}$ & Unclear risk & $\begin{array}{l}\text { No information about original protocol - insufficient information to make } \\
\text { judgement of risk }\end{array}$
\end{tabular}

\begin{tabular}{|c|c|c|}
\hline Other bias & Unclear risk & Baseline characteristics - balanced \\
\hline
\end{tabular}

Renko 2007

\begin{tabular}{ll}
\hline Methods & Non-blinded, parallel-group, randomised controlled trial with 6 months duration of follow-up \\
\hline Participants & Setting: 3 tertiary care paediatric hospitals in Finland, between 1999 and 2003 \\
& Sample size: \\
- Number randomised: 28 \\
- Number completed: 26 included in analysis at 6 months $(2 / 28(7.1 \%)$ lost to follow-up, 1 in each \\
group)
\end{tabular}

\section{Participant (baseline) characteristics:}

- Age: 1.5 to 14 years

- Gender: number male 8 (57\%) tonsillectomy group; 8 (67\%) control group

- Type of symptoms:

* In $41 \%$ of the cases the fever was the only symptom during the episodes, $29 \%$ had exudative tonsillitis during at least 1 of the episodes and $21 \%$ had either cervical lymphadenopathy, aphthous stomatitis or pain in the mouth or throat

* Number of children without other symptoms other than fever: $7 / 14$ (50\%) in tonsillectomy group and $4 / 12$ in control group (33\%)

- Imbalance between groups in number of children without any other symptom than fever (7 (50\%) versus $4(33 \%))$

\section{Inclusion criteria:}

- Children with at least 5 PFAPA attacks. The criteria for an attack were:

a. high fever $\left(\geq 38.5^{\circ} \mathrm{C}\right)$ of unknown origin recurring with a typical; and

b. regular pattern and asymptomatic intervals of 2 to 5 weeks; with or without

c. accompanying signs of aphthous stomatitis, pharyngitis and adenitis

Exclusion criteria: none described 


\section{Comparator group:}

- No treatment (watchful waiting); $n=13$ ( $N=12$ included in analysis)

\section{Use of additional medication/treatment (common to both groups):}

- Not adequately described. In the control group tonsillectomy was allowed after 6 months if the child's symptoms persisted

Patients were followed up with symptom diaries for 12 months

\begin{tabular}{ll}
\hline Outcomes & Primary outcome: \\
& $\begin{array}{l}\text { Disappearance of fever episodes according to symptom diaries at } 6 \text { months (measured by proportion } \\
\text { of participants with disappearance of symptoms) }\end{array}$ \\
& $\begin{array}{l}\text { Secondary outcome: } \\
\text { - Number of periodic fever episodes per person-month at risk }\end{array}$ \\
\hline Funding sources & Not stated \\
\hline Declarations of interest & Not stated \\
\hline Notes & Proportion of children in treatment group that did not receive surgery: not described \\
& $\begin{array}{l}\text { Proportion of children in control group receiving for surgical treatment: } 5 / 12 \text { (42\%); all children } \\
\text { underwent tonsillectomy after the follow-up period of at least } 6 \text { months } \\
*\end{array}$ \\
\hline
\end{tabular}

\section{Risk of bias}

\begin{tabular}{|c|c|c|}
\hline Bias & Authors' judgement & Support for judgement \\
\hline \multirow{3}{*}{$\begin{array}{l}\text { Random sequence genera- } \\
\text { tion (selection bias) }\end{array}$} & Low risk & Quotes: "The participants were randomly allocated" \\
\hline & & "A balanced randomisation was used at each centre to minimize bias" \\
\hline & & $\begin{array}{l}\text { The randomisation list was produced with a random number table (even num- } \\
\text { ber treatment A, odd number treatment B) (personal communication Renko } 4 \\
\text { October 2013) }\end{array}$ \\
\hline $\begin{array}{l}\text { Allocation concealment } \\
\text { (selection bias) }\end{array}$ & Low risk & $\begin{array}{l}\text { Opaque, sealed envelopes including the treatment choice were produced } \\
\text { along the randomisation list. So the person recruiting was not able to predict } \\
\text { the treatment group for the next patient (personal communication Renko } 4 \\
\text { October 2013) }\end{array}$ \\
\hline $\begin{array}{l}\text { Blinding of participants } \\
\text { and personnel (perfor- } \\
\text { mance bias) } \\
\text { All outcomes }\end{array}$ & Unclear risk & No blinding: unclear if this may affect the treatment of the control arm \\
\hline $\begin{array}{l}\text { Blinding of outcome as- } \\
\text { sessment (detection bias) } \\
\text { All outcomes }\end{array}$ & Unclear risk & No blinding, but treatment unlikely to be affected \\
\hline
\end{tabular}


Renko 2007 (Continued)

\begin{tabular}{|c|c|c|}
\hline $\begin{array}{l}\text { Incomplete outcome data } \\
\text { (attrition bias) }\end{array}$ & Low risk & $\begin{array}{l}\text { Low number of missing data (total: missing data balanced across intervention } \\
\text { groups ( } 1 \text { in each) and reason in } 1 \text { instance not related to outcome of interest). }\end{array}$ \\
\hline
\end{tabular}

(attrition bias)

All outcomes
Unclear risk porting bias)
Study methods section mentioned that all patients were followed up for 12 months, but only the data for 6 months of follow-up were reported

\begin{tabular}{|c|c|c|}
\hline Other bias & Unclear risk & $\begin{array}{l}\text { Baseline characteristics - imbalance between groups in number of children } \\
\text { without any symptom other than fever ( } 7(50 \%) \text { versus } 4(33 \%))\end{array}$ \\
\hline
\end{tabular}

ENT: ear, nose and throat

ITT: intention-to-treat

PFAPA: periodic fever, aphthous stomatitis, pharyngitis and cervical adenitis syndrome

Characteristics of excluded studies [ordered by study ID]

\begin{tabular}{ll}
\hline Study & Reason for exclusion \\
\hline Erdogan 2016 & ALLOCATION: non-randomised, retrospective cohort study \\
\hline Ibáñez Alcalde 2017 & ALLOCATION: non-randomised, retrospective cohort study \\
\hline Peridis 2010a & ALLOCATION: non-randomised cohort study \\
\hline Pignataro 2009 & ALLOCATION: non-randomised cohort study \\
\hline Ridder 2011 & ALLOCATION: non-randomised cohort study \\
\hline Vigo 2014 & ALLOCATION: non-randomised, retrospective cohort study \\
\hline
\end{tabular}

Characteristics of ongoing studies [ordered by study ID]

NCT03331497

Trial name or title

Methods

Participants

Interventions
Tonsillotomy or follow-up in PFAPA syndrome

Randomised, open-label, parallel-group randomised controlled trial

Children (aged 1 to 12 years) with PFAPA syndrome: regularly occurring fever episodes for 3 to 5 days at least 5 times or for 6 months

Intervention group: tonsillotomy (monitoring for 3 months: if symptoms persist tonsillectomy will be performed)

Comparator group: no intervention (monitoring for 3 months: if symptoms persist tonsillectomy will be performed)

Outcomes Primary outcome:

Cure (proportion of patients who do not have any PFAPA symptoms at 3 months)

\section{Secondary outcomes:}

Rescue surgery: tonsillectomy (at 12 months) 
NCT03331497 (Continued)

Days with fever (number of days with fever $>38^{\circ} \mathrm{C}$ in symptom diaries)

\begin{tabular}{ll}
\hline Starting date & 24 October 2017 \\
\hline Contact information & Dr Marjo Renko, Oulu University Hospital, Oulu, Finland (marjo.renko@oulu.fi) \\
\hline Notes & Estimated study completion date May 2020 \\
\hline
\end{tabular}

PFAPA: periodic fever, aphthous stomatitis, pharyngitis and cervical adenitis syndrome

\section{DATA AND ANALYSES}

Comparison 1. Surgery (tonsillectomy +/-adenoidectomy) versus control

\begin{tabular}{lllll}
\hline Outcome or subgroup title & $\begin{array}{l}\text { No. of } \\
\text { studies }\end{array}$ & $\begin{array}{l}\text { No. of } \\
\text { partici- } \\
\text { pants }\end{array}$ & Statistical method & Effect size \\
\hline $\begin{array}{l}1 \text { Proportion of patients whose symptoms have } \\
\text { completely resolved }\end{array}$ & 2 & 65 & Risk Ratio (M-H, Random, 95\% Cl) & $4.38[0.64,30.11]$ \\
\hline $\begin{array}{l}2 \text { Number of episodes of fever and associated } \\
\text { symptoms (per person-month) }\end{array}$ & 2 & 65 & Rate Ratio (Fixed, 95\% Cl) & $0.08[0.05,0.13]$ \\
\hline 3 Use of corticosteroids & 1 & 39 & Risk Ratio (M-H, Fixed, 95\% Cl) & $0.58[0.37,0.92]$ \\
\hline
\end{tabular}

Analysis 1.1. Comparison 1 Surgery (tonsillectomy +/- adenoidectomy) versus control, Outcome 1 Proportion of patients whose symptoms have completely resolved.

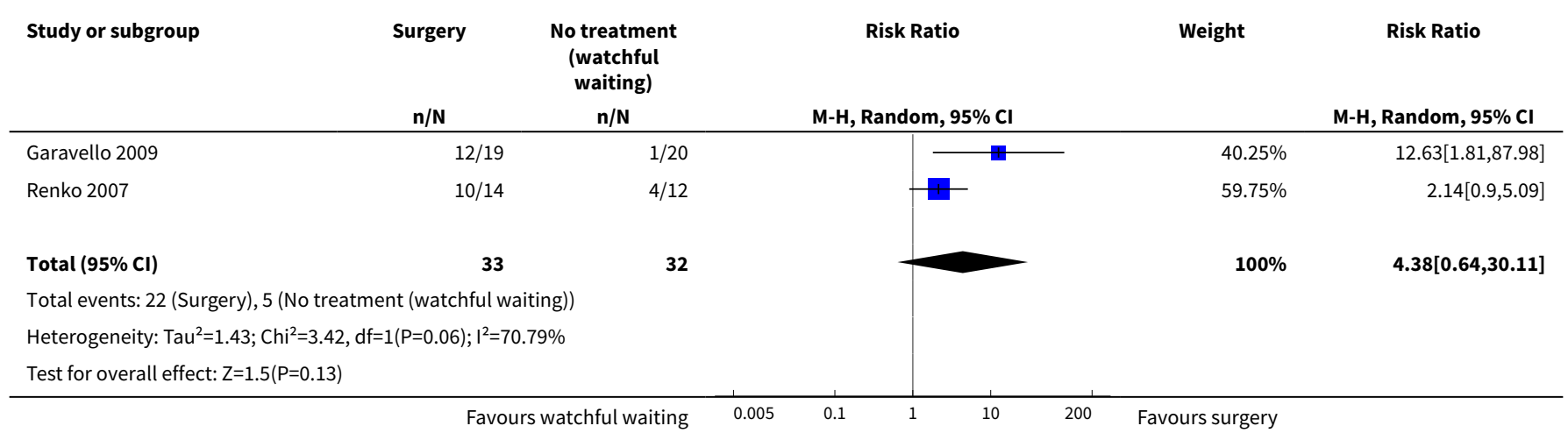


Analysis 1.2. Comparison 1 Surgery (tonsillectomy +/- adenoidectomy) versus control, Outcome 2 Number of episodes of fever and associated symptoms (per person-month).

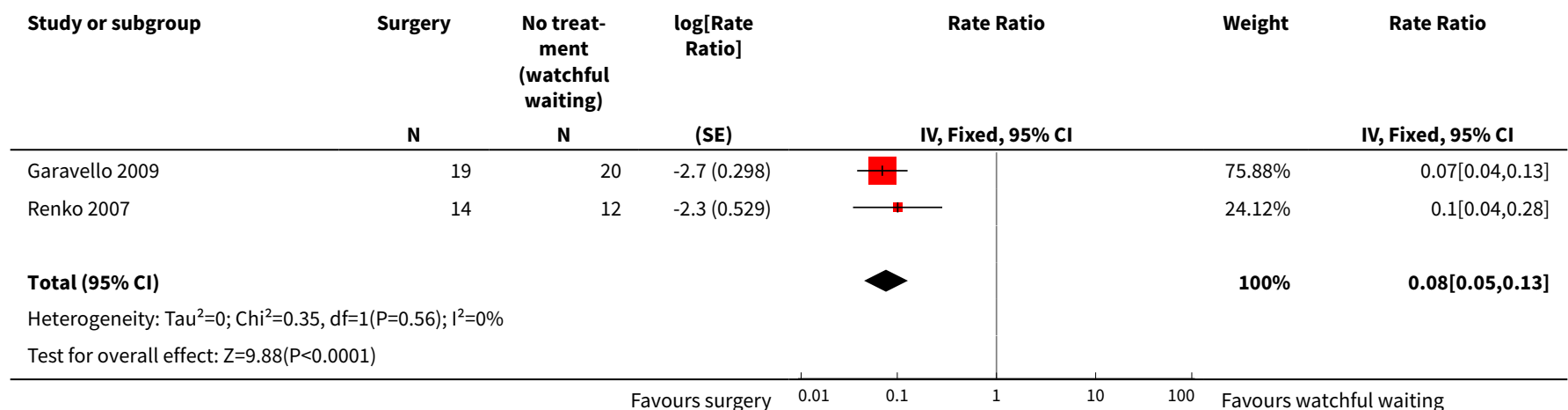

Analysis 1.3. Comparison 1 Surgery (tonsillectomy $+/-$ adenoidectomy) versus control, Outcome 3 Use of corticosteroids.

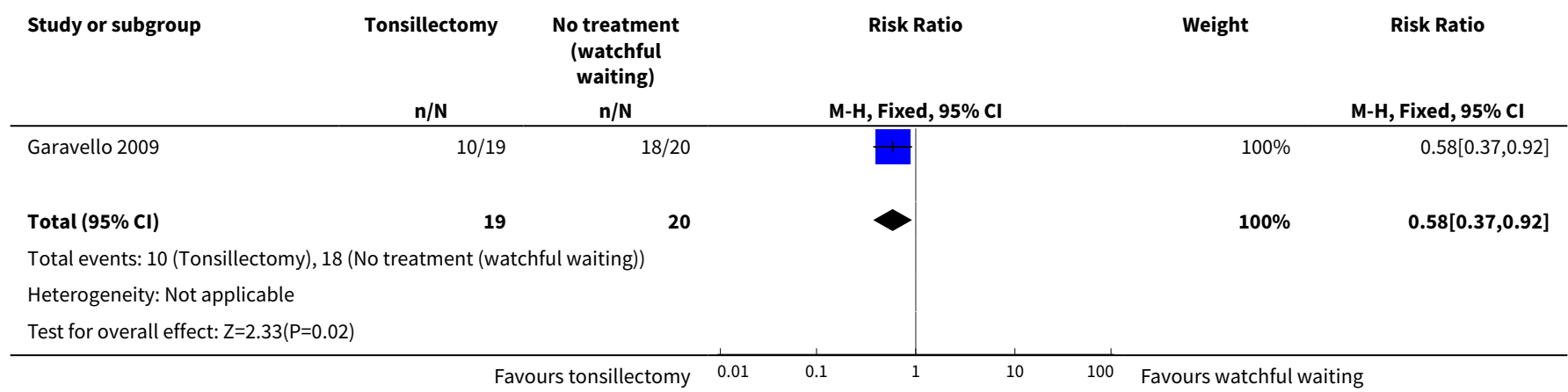

\section{APPENDICES}

Appendix 1. Search strategies

\begin{tabular}{|c|c|c|c|}
\hline CENTRAL & PubMed & EMBASE (Ovid) & CINAHL (EBSCO) \\
\hline $\begin{array}{l}\text { \#1 PFAPA or marshall*:ti } \\
\text { \#2 MeSH descriptor Fever explode all trees } \\
\text { \#3 fever } \\
\text { \#4 MeSH descriptor Stomatitis explode all } \\
\text { trees } \\
\text { \#5 Stomatitis or Oromucositis or (oral and } \\
\text { mucositis) } \\
\text { \#6 (aphthous OR aphtosus) AND lesion* } \\
\text { \#7 MeSH descriptor Pharyngitis explode all } \\
\text { trees } \\
\text { \#8 pharyngitis } \\
\text { \#9 MeSH descriptor Lymphadenitis explode } \\
\text { all trees }\end{array}$ & $\begin{array}{l}\text { \#1 PFAPA OR (marshall* } \\
\text { AND syndrome*) } \\
\text { \#2 “FEVER" [Mesh] OR } \\
\text { fever* } \\
\text { \#3 “STOMATITIS" [Mesh] } \\
\text { OR stomatitis OR Oromu- } \\
\text { cositis OR (oral AND mu- } \\
\text { cositis) } \\
\text { \#4 (aphthous OR aphto- } \\
\text { sus) AND lesion* } \\
\text { \#5 “PHARYNGITIS" [Mesh] } \\
\text { OR pharyngitis } \\
\text { \#6 “Lymphadeni- } \\
\text { tis" [Mesh] OR adenitis }\end{array}$ & $\begin{array}{l}\text { 1. PFAPA.mp. or } \\
\text { "marshall* syn- } \\
\text { drome*”.mp. } \\
\text { 2. exp fever/ } \\
\text { 3. FEVER*.mp. } \\
\text { 4. exp stomatitis/ } \\
\text { 5. (Stomatitis or } \\
\text { Oromucositis or } \\
\text { (oral and mucosi- } \\
\text { tis)).mp. } \\
\text { 6. ((aphthous or } \\
\text { aphtosus) and le- } \\
\text { sion*).mp. } \\
\text { 7. exp pharyngitis/ }\end{array}$ & $\begin{array}{l}\text { S1 TX PFAPA or "Marshall* syn- } \\
\text { drome*" } \\
\text { S2 (MH "Fever+") } \\
\text { S3 TX FEVER* } \\
\text { S4 S2 or S3 } \\
\text { S5 (MH "Stomatitis+") } \\
\text { S6 TX Stomatitis or Oromucosi- } \\
\text { tis or (oral and mucositis) } \\
\text { S7 TX (aphthous or aphtosus) } \\
\text { and lesion* } \\
\text { S8 (S5 or S6 or S7) } \\
\text { S9 (MH "Pharyngitis") } \\
\text { S10 TX PHARYNGITIS } \\
\text { S11 (S9 or S10) }\end{array}$ \\
\hline
\end{tabular}


(Continued)

\#10 adenitis OR adenitides OR lymphadenitis OR lymphadenitides

\#11 (( \#2 OR \#3 ) AND ( \#4 OR \#5 OR \#6 ) AND

( \#7 OR \#8 ) AND ( \#9 OR \#10))

\#12 (\#1 OR \#11)

\#13 MeSH descriptor Tonsillectomy explode all trees

\#14 MeSH descriptor Palatine Tonsil explode all trees with qualifier: $\mathrm{SU}$

\#15 (tonsillectom* OR tonsilectom ${ }^{*}$ OR adenotonsillectom * OR adenotonsilectom* OR tonsillotom ${ }^{\star}$ OR tonsilotom ${ }^{\star}$ )

\#16 MeSH descriptor Tonsillitis explode all

trees

\#17 MeSH descriptor Palatine Tonsil explode all trees

\#18 (tonsil $^{\star}$ OR adenotonsil ${ }^{\star}$ )

\#19 (\#16 OR \#17 OR \#18)

\#20 MeSH descriptor Surgical Procedures,

Operative explode all trees

\#21 (surg*:ti OR excis*:ti OR extract*:ti OR remov*:ti)

\#22 (\#20 OR \#21)

\#23 (\#19 AND \#22)

\#24 (\#13 OR \#14 OR \#15 OR \#23)

\#25 (\#12 AND \#24)
OR adenitides OR lymphadenitis OR lymphadenitides

\#7 \#2 AND \#3 AND \#4 AND \#5 AND \#6

\#8 \#1 OR \#7

\#9 "Tonsillectomy" [Mesh]

OR "Palatine Tonsil/surgery"[Mesh] OR

(tonsillectom ${ }^{\star}$ OR tonsilectom* OR adenotonsillectom* OR adenotonsilectom* OR tonsillotom * OR tonsilotom *)

\#10 "Tonsillitis"[MeSH] OR "Palatine Tonsil" [MeSH] OR tonsil ${ }^{\star}$ OR adenoton$\left.\mathrm{sil}^{\star}\right)$

\#11 "Surgical Procedures, Operative" [Mesh] OR surg $^{\star}[\mathrm{ti}]$ OR excis*[ti] OR extract ${ }^{\star}[\mathrm{ti}]$ OR remov ${ }^{\star}[\mathrm{ti}]$ \#12 \#10 AND \#11 \#13 \#9 OR \#12 \#14 \#8 AND \#13
8. pharyngitis.mp. 9. exp lymphadenitis/

10. (adenitis or adenitides or lymphadenitis or lymphadenitides).mp. 11. ( 2 or 3 ) and ( 4 or 5 or 6$)$ and (7 or 8 ) and (9 or 10 )

12. 1 or 11

13. exp tonsillectomy/

14. exp tonsil disease/su [Surgery] 15. (tonsillectom* or tonsilectom* or adenotonsillectom* or adenotonsilectom* or tonsillo-

tom ${ }^{\star}$ or posttonsillectom*).tw. 16. 13 or 14 or 15

17. exp tonsil/

18. exp tonsillitis/

19. (tonsil* or adenotonsil $\left.{ }^{\star}\right)$.tw.

20. 17 or 18 or 19

21. exp surgery/

22. exp surgical technique/

23. (surg* or operat ${ }^{\star}$ or remov* or preop* or periop* or postop ${ }^{\star}$.ti,ab.

24. 21 or 22 or 23

25. 20 and 24

26. 16 or 25

27. 12 and 26
S12 (MH "Lymphadenitis+")

S13 TX Lymphadenitis

S14 (S12 or S13)

S15 (S4 and S8 and S11 and S14)

S16 S1 OR S15

S17 (MH "Tonsillectomy")

S18 (MH "Tonsil/SU")

S19 (MH "Tonsil")

S20 TX tonsil ${ }^{*}$ OR adenotonsil ${ }^{\star}$

S21 S19 or S20

S22 (MH "Surgery, Operative")

S23 TX surg* or operat* or remov $^{\star}$ or preop* or periop* or postop*

S24 S22 or S23

S25 S21 and S24

S26 TX tonsillectom* OR postonsillectom* ${ }^{\star} \mathrm{R}$ adenotonsillectom* OR tonsillotom* S27 S17 or S18 or S25 or S26

S28 S16 AND S27

\section{Cochrane ENT Register (via CRS)}

\section{CAB Abstracts (Ovid)}

\section{Web of Science (Web of Knowl- edge)}

\section{PFAPA or marshall*::AB,EH,KW,KY,M- C,MH,TI,TO AND INREGISTER \\ 2 MESH DESCRIPTOR fever EXPLODE ALL AND INREGISTER

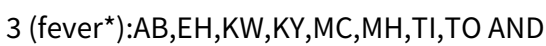 INREGISTER \\ 4 MESH DESCRIPTOR Stomatitis EXPLODE ALL AND INREGISTER}

5 (Stomatitis or Oromucositis or (oral and mucositis)):AB, EH, KW, KY,MC,MH,TI,TO AND INREGISTER

6 (aphthous OR aphtosus) AND lesion* AND INREGISTER
1. PFAPA.mp. or "mar- shall* syndrome*”.mp.
2. exp fever/
3. FEVER ${ }^{\star}$.mp.
4. exp stomatitis/
5. (Stomatitis or Oromu- cositis or (oral and mu- cositis)).mp. [mp=ab- stract, title, original ti- tle, broad terms, heading words]
6. ((aphthous or aphtosus) and lesion $\left.{ }^{\star}\right)$.mp.
7. exp pharyngitis/
8. pharyngitis.mp
9. exp lymphadenitis/
\#1 TS=(tonsil ${ }^{*}$ or adenotonsil*) \#2 TS=(surg* or op- erat $^{\star}$ or remov* or preop* or periop* or postop $\left.{ }^{\star}\right)$ \#3 TS=(tonsillec- tom* or adenoton- sillectom ${ }^{\star}$ or tonsil- lotom ${ }^{\star}$ or postton- sillectom*) \#4 \#2 AND \#1 \#5 \#4 OR \#3 \#6 Title=(PFAPA or marshall*) OR Ti- tle $=\left(\right.$ FEVER ${ }^{\star}$ AND

\section{Trial registries}

\section{ICTRP via the WHO Portal}

PFAPA AND tonsil ${ }^{*}$ OR marshall ${ }^{*}$ AND tonsil* OR aphthous AND tonsil ${ }^{*}$ OR aphtosus AND tonsil ${ }^{*}$

\section{CT.gov via Clinicaltrials.gov}

(PFAPA OR marshall or Marshalls OR aphthous OR aphtosus) AND (tonsils OR tonsil OR tonsilectomy OR tonsillectomy OR adenotonsillectomy OR adenotonsilectomy)

\section{CT.gov and ICTRP via CRS (in- cluding CENTRAL)}


(Continued)

7 MESH DESCRIPTOR Pharyngitis EXPLODE ALL AND INREGISTER

8 (Pharyngitis):AB, EH,KW,KY,MC,MH,TI,TO AND INREGISTER

9 MESH DESCRIPTOR Lymphadenitis EXPLODE ALL AND INREGISTER

10 (adenitis OR adenitides OR lymphadenitis OR lymphadenitides): $A B, E H, K W, K Y, M-$ $\mathrm{C}, \mathrm{MH}, \mathrm{TI}, \mathrm{TO}$ AND INREGISTER

11 ((\#2 OR \#3) AND (\#4 OR \#5 OR \#6) AND (\#7 OR \#8) AND (\#9 OR \#10)) AND INREGISTER

\section{2 \#11 OR \#1 AND INREGISTER}

13 MESH DESCRIPTOR Tonsillectomy EXPLODE ALL AND INREGISTER

14 MESH DESCRIPTOR Palatine Tonsil EXPLODE ALL WITH QUALIFIER SU AND INREGISTER

15 ((tonsillectom* OR tonsilectom* OR adenotonsillectom ${ }^{\star} \mathrm{OR}$ adenotonsilectom * OR tonsillotom ${ }^{\star}$ OR tonsilotom $\left.\left.{ }^{\star}\right)\right): A B, E H, K-$ W,KY,MC,MH,TI,TO AND INREGISTER

16 MESH DESCRIPTOR Tonsillitis EXPLODE ALL AND INREGISTER

17 MESH DESCRIPTOR Palatine Tonsil EXPLODE ALL AND INREGISTER

$18\left(\left(\right.\right.$ tonsil $^{\star} \mathrm{OR}$ adenotonsil $\left.\left.{ }^{\star}\right)\right): \mathrm{AB}, \mathrm{EH}, \mathrm{K}-$ W,KY,MC,MH,TI,TO AND INREGISTER

\section{9 \#16 OR \#17 OR \#18 AND INREGISTER}

20 MESH DESCRIPTOR Surgical Procedures, Operative EXPLODE ALL AND INREGISTER

21 (surg* OR excis* OR extract ${ }^{\star}$ OR remov $\left.^{\star}\right)$ :ti AND INREGISTER

22 \#20 OR \#21 AND INREGISTER

23 \#19 AND \#22 AND INREGISTER

24 \#13 OR \#14 OR \#15 OR \#23 AND INREGISTER

25 \#24 AND \#12 AND INREGISTER
10. (adenitis or adenitides or lymphadenitis or lymphadenitides).mp. [mp=abstract, title, original title, broad terms, heading words] 11. ( 2 or 3$)$ and ( 4 or 5 or 6$)$ and ( 7 or 8$)$ and (9 or 10) 12. 1 or 11

13. (tonsillectom ${ }^{*}$ or tonsilectom ${ }^{\star}$ or adenotonsillectom ${ }^{\star}$ or adenotonsilectom ${ }^{\star}$ or tonsillotom ${ }^{\star}$ or posttonsillectom $\left.{ }^{\star}\right)$.tw. 14. tonsils/ 15. tonsillitis/

16. (tonsil ${ }^{\star}$ or adenotonsil $\left.{ }^{\star}\right)$.tw.

17. 14 or 15 or 16

18. exp surgery/

19. exp surgical opera-

tions/

20. (surg* or operat $^{\star}$ or remov $^{\star}$ or preop* or periop* or postop $\left.{ }^{\star}\right)$.ti,ab.

21. 18 or 19 or 20

22. 17 and 21

23. 13 or 22
(Stomatitis or Oromucositis aphthous or aphtosus) AND PHARYNGITIS AND (adenitis or adenitides or lymphadenitis or lymphadenitides)) \#7 \#6 AND \#5
1 (PFAPA OR marshall ${ }^{\star}$ OR aphthous OR aphtosus) AND (tonsil $^{*}$ or adenotonsil $\left.{ }^{\star}\right)$ AND INREGISTER

2 (PFAPA OR marshall* OR aphthous OR aphtosus) AND (tonsil $^{\star}$ or adenotonsil*) AND CENTRAL:TARGET

\section{3 \#1 OR \#2 AND CENTRAL:TAR-} GET

4 (NCTO* $^{*}$ or ACTRN ${ }^{\star}$ or ChiCTR* or DRKS ${ }^{\star}$ or EUCTR ${ }^{\star}$ or eudract ${ }^{\star}$ or IRCT* ${ }^{\star}$ or ISRCTN ${ }^{\star}$ or JapicC$\mathrm{TI}^{\star}$ or JPRN ${ }^{\star}$ or NTR0* or NTR1 * or NTR2 ${ }^{\star}$ or NTR3* ${ }^{*}$ or NTR4* ${ }^{\star}$ or NTR5 ${ }^{\star}$ or NTR6 ${ }^{\star}$ or NTR7 ${ }^{\star}$ or NTR8* or NTR9* or SRCTN* or UMINO*):AU AND INREGISTER

5 (NCTO* or ACTRN* or ChiCTR* or DRKS ${ }^{\star}$ or EUCTR ${ }^{\star}$ or eudract ${ }^{\star}$ or IRCT* or ISRCTN* or JapicC$\mathrm{TI}^{\star}$ or JPRN ${ }^{\star}$ or NTR0* or NTR1* or NTR2* or NTR3* or NTR4* or NTR5 ${ }^{*}$ or NTR6 ${ }^{\star}$ or NTR $7^{\star}$ or NTR8 ${ }^{\star}$ or NTR9* or SRCTN* or UMINO*):AU AND CENTRAL:TARGET

6 http*:SO AND INREGISTER

7 http $^{\star}:$ SO AND CENTRAL:TARGET

8 \#4 OR \#5 OR \#6 OR \#7 AND CENTRAL:TARGET

9 \#3 AND \#8 AND CENTRAL:TARGET

\section{WHAT'S NEW}




\begin{tabular}{lll}
\hline Date & Event & Description \\
\hline 15 October 2019 & New search has been performed & Searches updated 15 October 2019. \\
\hline 15 October 2019 & $\begin{array}{l}\text { New citation required but conclusions } \\
\text { have not changed }\end{array}$ & $\begin{array}{l}\text { We identified no new included studies with our searches in Octo- } \\
\text { ber 2019. We excluded a further three studies. One randomised } \\
\text { controlled trial is ongoing, with completion estimated for May } \\
\text { 2020. There are no changes to the conclusions of the review. }\end{array}$ \\
\hline
\end{tabular}

\section{H I S T O R Y}

Review first published: Issue 9, 2010

\begin{tabular}{|c|c|c|}
\hline Date & Event & Description \\
\hline \multirow[t]{5}{*}{31 March 2014} & New search has been performed & $\begin{array}{l}\text { New searches run and update completed. Summary of key } \\
\text { changes: }\end{array}$ \\
\hline & & 1. New outcomes added to protocol. \\
\hline & & $\begin{array}{l}\text { 2. A 'Summary of findings' table is now presented. Quality of evi- } \\
\text { dence is now described based on the GRADE framework. }\end{array}$ \\
\hline & & $\begin{array}{l}\text { 3. New data were available from Renko } 2007 \text { : number with im- } \\
\text { mediate and complete symptom resolution. Analysis } 1.1 \text { now } \\
\text { pools this outcome. This change has not altered our conclu- } \\
\text { sions. }\end{array}$ \\
\hline & & $\begin{array}{l}\text { Two new authors joined in July } 2013 \text { (Roderick Venekamp and } \\
\text { Lee Yee Chong). }\end{array}$ \\
\hline \multirow[t]{2}{*}{30 March 2014} & $\begin{array}{l}\text { New citation required but conclusions } \\
\text { have not changed }\end{array}$ & $\begin{array}{l}\text { As no additional trials were identified, the conclusions and rec- } \\
\text { ommendations regarding the effectiveness of tonsillectomy ver- } \\
\text { sus non-surgical treatment in children with PFAPA syndrome re- } \\
\text { main unchanged. }\end{array}$ \\
\hline & & $\begin{array}{l}\text { The effectiveness of tonsillectomy in children with PFAPA syn- } \\
\text { drome finding is derived from two small RCTs. These trials re- } \\
\text { ported significant beneficial effects of surgery as compared to no } \\
\text { surgery on immediate and complete symptom resolution (NNTB } \\
=2 \text { ) and a substantial reduction in the frequency and severity } \\
\text { (length of episode) of any further symptoms experienced. How- } \\
\text { ever, the evidence is of moderate quality (further research is like- } \\
\text { ly to have an important impact on our confidence in the esti- } \\
\text { mate of effect and may change the estimate) due to the relative- } \\
\text { ly small sample sizes of the studies and some concerns about } \\
\text { the applicability of the results. Therefore, the parents and car- } \\
\text { ers of children with PFAPA syndrome must weigh the risks and } \\
\text { consequences of surgery against the alternative of using medica- } \\
\text { tion, as it is well established that children with PFAPA syndrome } \\
\text { recover spontaneously and medication can be administered to } \\
\text { try and reduce the severity of individual episodes. It is uncertain } \\
\text { whether adenoidectomy combined with tonsillectomy adds any } \\
\text { additional benefit to tonsillectomy alone. }\end{array}$ \\
\hline
\end{tabular}

\section{CONTRIBUTIONS OF AUTHORS}

Martin Burton: conceived protocol, extracted data, conducted analysis, reported results, contributed to final paper. 
Andrew Pollard: conceived protocol, contributed to final paper.

James Ramsden: conceived protocol, extracted data, conducted analysis, reported results, contributed to final paper.

Roderick Venekamp: conducted searches, identified studies, extracted data, conducted analysis and prepared manuscript for the updated review in 2014.

Lee Yee Chong: identified studies, contacted authors, extracted data, conducted analysis and prepared manuscript for the update review in 2014.

All authors have reviewed and provided comment on the updated version of the review.

\section{DECLARATIONS OF INTEREST}

Martin J Burton: Professor Martin Burton is joint Co-ordinating Editor of Cochrane ENT, but had no role in the editorial sign-off process for this review.

Andrew J Pollard: none known.

James D Ramsden: none known.

Lee-Yee Chong: none known.

Roderick P Venekamp: none known.

\section{SOURCES OF SUPPORT}

\section{Internal sources}

- No sources of support supplied

\section{External sources}

- National Institute for Health Research, UK.

Infrastructure funding for Cochrane ENT

\section{DIFFERENCES BETWEEN PROTOCOLAND REVIEW}

In the 2014 update, we expanded the objective of the review to include evaluation of both clinical effectiveness and safety. We added additional outcomes to the review protocol, to ensure that both potential harms and benefits that are important to patients were captured in the review. These were complications of surgery (haemorrhage and number of days with postoperative pain), number of courses of corticosteroids, absence or time off school and quality of life.

In the 2019 update, we revised the inclusion criteria to clarify that we would include studies in which participants had received tonsillotomy (partial tonsillectomy) (Types of interventions). We also made some minor changes to the Methods section to bring the review into line with the current format. In addition, we added a subsection describing the methods used for applying GRADE and creating the 'Summary of findings' table.

\section{IN DEX TERMS}

\section{Medical Subject Headings (MeSH)}

*Tonsillectomy; Adenoidectomy; Fever [ ${ }^{*}$ surgery]; Lymphadenitis [surgery]; Neck; Periodicity; Pharyngitis [ ${ }^{\star}$ surgery]; Randomized Controlled Trials as Topic; Remission, Spontaneous; Stomatitis, Aphthous [*surgery]; Syndrome; Watchful Waiting

\section{MeSH check words}

Adolescent; Child; Child, Preschool; Humans; Infant 